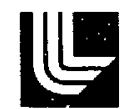

LAWRENCE LMERMORE LABORATORY

Unversity of Calitomia, Livermore, Calitomia/94550

\author{
UCRL-50022-4
}

\title{
LLL LASER PROJECTS REPORT NO. 4
}

\author{
Edited by George I. Kachen \\ Stanley S. Sussman \\ Wallace Clements
}

MS. date: March 1973

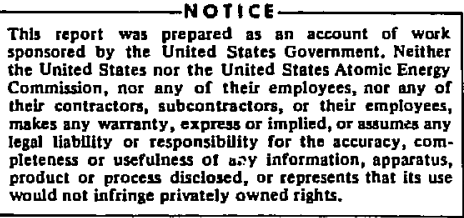

would not infringe privately owned rights. 


\section{Foreword}

The articles appearing in this document are reprints from other Lawrence Livermore Laboratory reports published in recent months. Therefore, the numbering of such items as figures, tables, and ruferences is not aecessarily sequential throughout the document and does not begin with "one."

Some of the articles make reference to company or product names. Such reference does not imply approval or recommendation of the product by the University of California or the U.S. Atomic Energy Commission to the exclusion of others that may be suitable. 
Contents

Stimulated Vacuum-Utraviolet Emission from High-Pressure Xenon Excited by Pulsed High-Energy Electron Beams (Helmut A. Koehler, Lawrence J. Ferderber, David L. Redhead, and Paul J. Ebert)

A Cylindrical, Ring -Electrode Pockets Cell for Isolating Fast Pulses of Laser Light (Lloyd L. Steinmetz, Bertram C. Johnson, and Thomas W. Pouliot)

X-Ray Conversion Efficiencies of LesenProduced Miasmas (Charles E. Violet, S. Warren Mead, William H. Grasberger, and Joseph Peruzzi)

Techniques for Optically Isolating the Components of Lase: Systems (Earl F. Wooden, Lloyd L. Steinmetz, Scott J. Thomas, and Bertram C. Johnson) . . . . . . . . . . . . . . . . . 8

Calculations of the Laser Heating of $\approx$ Deuterium Target (Jay D. Chase, James M. LeBlanc, and James R. Wilson) . . . . . . . . . . . . . . II

A New Approach for Demontuting the Feaslillity of Efficient Pulsed Chemical Lowers (Charles E. Timer, Jr., Yu-Li Pan, and Dennis J. Blaster)

13

Self -Focusing Damage in Nd:Gias Amplifier

(Clyde B. Lane and Joseph A. Fleck, Jr.) . . . . . . . . . . . . . . . . . . . . . . . 18

Holography Applications and Research

(Gilbert W. Leppelmeier and Henry H. Chou) . . . . . . . . . . . . . . . . . . . . 20

A Lape-Aperture TEA $\mathrm{CO}_{2}$ Amplifier (Kenneth $R$. Manes, Stanley S. Glares, and Kenneth J. Pettiplece) . . . . . . . . . . . . . . . . . . . . . 23

Short-Pube Generation and Amplification in a $\mathrm{CO}_{2}$ TEA Leer Oscillutor-Amplifier (Claude R. Phipps, Jr., Kenneth R. Manes, and scott J. Thomas)

25

Nates and Roforonces . . . . . . . . . . . . . . . . . . . . . . 29

iii -iv 
Most experimental studies of the continuum emission by the rare gases in the vacuum-ultraviolet have been done at gas pressures of less than 20 psi. ${ }^{14}$ The gases have usually been excited by electrical discharge or microwaves, although some recent studies have used highenergy charged particles. Current interest in the vacuum.UV emission from the rare gases stems from the possibility that these elements can undergo high-power vacuum-UV lasing. $15-17$ Since little information is available on the emission from high-pressure rare gases excited by high-current, high-energy electron beams, we have studied the emission characteristics of xenon under those conditions.

\section{Experimental Apparatus}

Our experimental spparatus, shown schematically in Fig. 9, consisted of a source of electrons, electron-beam monitors (not showa), a gas cell capable of holding pressures up to $1000 \mathrm{psi}$, and optical sensors for messuring the temporal, spatial, and spectral characteristics of the emission.

We used two electron-benm guns: one produces $2 \mathrm{MeV}$ electrons in pulses having durations of $50 \mathrm{nsec}$ FWHM (full width at half maximum), and the other produces 0.6-MeV electrons in pulses having durations of less than 2 nsec FWHM. Both generate electron currents up to $7000 \mathrm{~A}$. The entrance window for the electron beams was a piece of thin $(0.013 \mathrm{~cm})$ stainless steel, which was supported by a perforated steel plate to minimize bulging due to the high pressure.

The central volume of the gas was viewed through 2-mm-thick LiF or sapphire windows. The UV windows were mounted at the outer ends of $10-\mathrm{cm}-$ long line-of-sight pipes that extended from the central volume of the gas cell. Two of the windows were perpendicular to the axis of the electron beam, and a third faced directly along the axis. The line-of-sight pipes were filled with xenon gas at the ame pressure as in the central volume of the gas cell. Collimators protected the UV windows from stray electrons and $x$-rays, which could cause the windows to become opaque to UV radiation.

Three different sensors were used for observing the vacuum-UV radiation. To determine the spatial characteristics of the emission, we used a lensless Nikonos II underwater camera with Kodak type 101-10 UV-sensitive film. To obtain spectral information we used, in addition to this camera, a

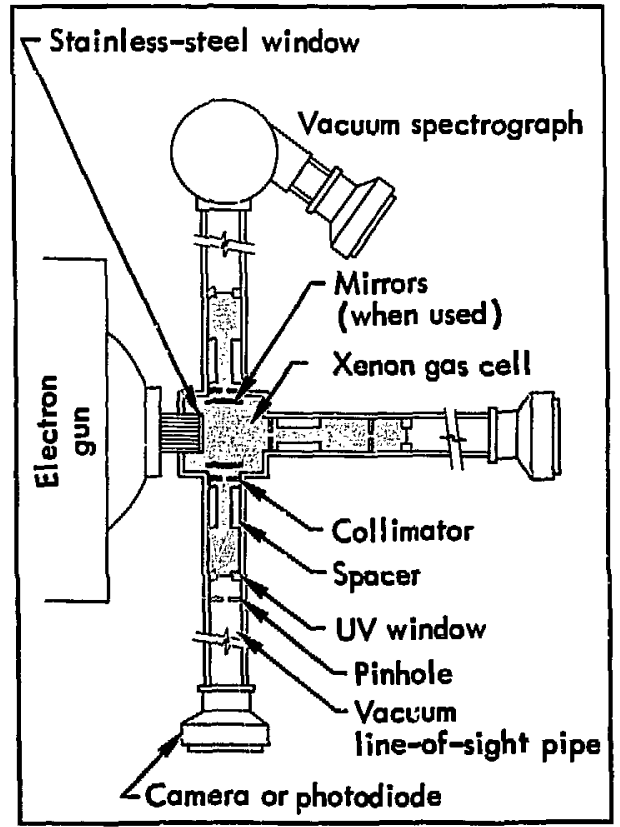

Fig. 9. Appantus for tudying the vecuum-ultrivalet emition from hightpresure xenon gas.

McPherson Model 235 vacuum spectrograph, which has a dispersion of $17 \mathrm{~A} / \mathrm{mm}$. To measure the time dependence of the emission, we used an ITT 4115 planar photodiode having \& 2.5-mm-thick $\mathrm{MgF}_{2}$ window and a CsTe photocathode. A vacuum of less than $10^{-3}$ Torr was maintained in the line-of-sight pipe between the UV windows and these sensors.

The xenon gas was Reagent grade; the concentrations of impurities were $12 \mathrm{ppm} \mathrm{H}_{2}, 3 \mathrm{ppm}$ $\mathrm{O}_{2}, 6 \mathrm{ppm} \mathrm{N}_{2}$, and about $100 \mathrm{ppm} \mathrm{Kr}$. The gas pressure ranged from 15 to $450 \mathrm{psi}$. We made no attempt to maintain uniform gas tempersture, but we found that our results were not reproducible unless we kepi the entrance window cool by blowing precooled dry nitrogen on it.

Results

Measurements made with the vacuum spectrograph showed that xerion emits a nearly symmetrical band 
of 150 A FWH (full width at half density) centered at $1700 \AA$. This spectrum was independent of pressure, although we observed some narrowing of the band when we decreased the current density of the electron beam (but kept the xenon pressure constant). No other emission was observed out to $7000 \AA$.

The 0.6-MeV electron pulse has a FWHM of less than 2 nsec. Except at very high pressures, this is so narrow that it approximates an impulse. Consequently, it can be used to determine the lifetimes of some of the species it creates. Figure 10 shows the variation with time of the $1700 \AA$ radiation emitted by xenon at different pressures when the gas is excited by the short pulse of electrons. We found that the time dependence of the intensity $I$ of the emission pulse could be approximated by the difference of two exponentials,

$$
I(t)=I_{0}\left(e^{-\lambda_{1} t}-e^{-\lambda_{2} t}\right)
$$

where $\lambda_{1}$ and $\lambda_{2}$ are the time constants for the decay and the buildup, respectively, of the emission pulse. We numerically fitted the observed pulses to Eq. (1), and determined that, for pressures less than $150 \mathrm{psi}$, $\lambda_{2}$ varied as the 1.7 power of the pressure $P$. Above $150 \mathrm{psi}$ the pressure dependence could not be accurately determined because the buildup time, $1 / \lambda_{2}$, approzches the width of the $0.6-\mathrm{MeV}$ excitation pulse. We analyzed the decay for times up to $40 \mathrm{nsec}$ after peak intensity and found it to be essentially independent of pressure: $1 / \lambda_{1} \approx 2 \times 10^{-8} \mathrm{sec}$.

When the xenon was excited by the wide ( $50 \mathrm{nsec}$ FWHM) 2-MeV electron pulse, we found that the peak UV output intensity varied as $P^{1.5}$ and that the FWHM of the emission pulse varied as $F^{-0.5}$. Thus, the UV energy output, which is given by the product of the peak intensity and the FWHM of the pulse, varied linearly with pressure. This pressure dependence was expected, since the amount of electron energy deposited in the gas increases linearly with pressure.

We also found that the UV emission intensity of xenon at 150 psi varied linearly with the current of the electron beam between 130 and 3300 A. The pulse shape did not change with the change in current.

To estimate the efficiency with which xenon converts the kinetic energy of the electrons into UV photons, we calculated the photon output from photodiode measurements and extimated the energy deposited in the gas from the characteristics of the electron beams. The energy $W$ deposited in the gas was estimated from the approximation

$$
W \approx I T \frac{d E}{d x} \rho x
$$

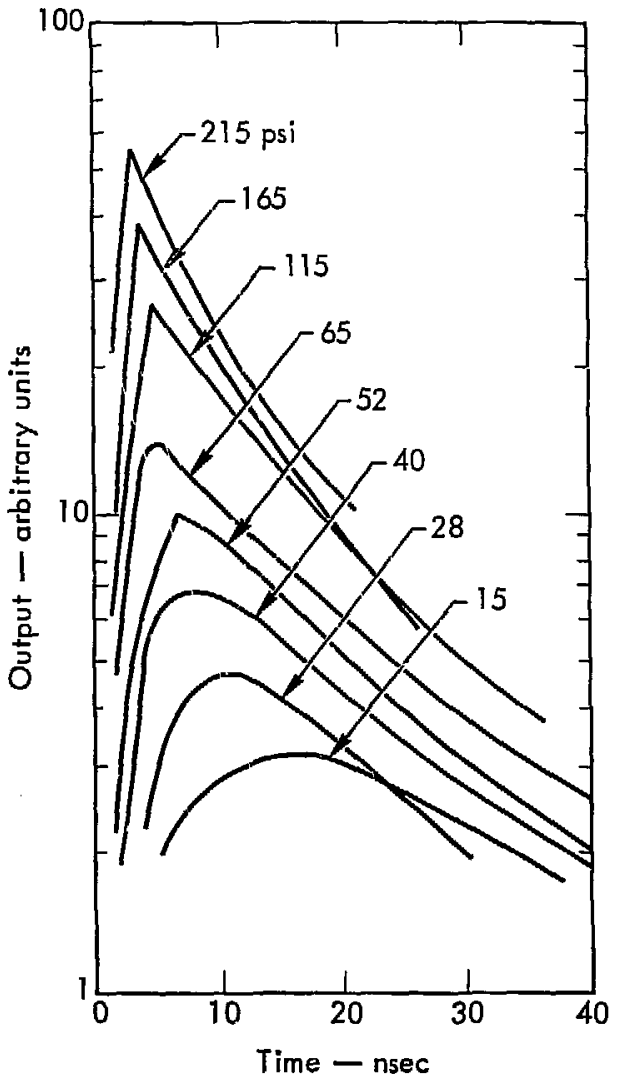

Fig. 10. The intensity of spontaneous 1700-A emission from xenon plotted as a iunction of time at different pressures. The gas was excitel by a 2-nsec (FWHM) banst of 0.6-MeV electrons.

where $I$ is the electron beam current, $\tau$ is the FWHM of the electron beam, $d E / d x$ is the rate of electron energy loss by collisions, $\rho$ is the density of the gas, and $x$ is the length along the beam axis that is observed through the defining collimators.

Using Eq. (2) we calculated that the efficiency of conversion of electron energy to $U V$ radiation in xenon at 250 psi was about $20 \%$ in our experiments. This corresponds, for example, to a peak UV power output of about $300 \mathrm{MW}$ and a UV photon density of about $1 \mathrm{~J} / \mathrm{cm}^{3}$. Our results compare favorably with those of Hurst $e t a l .,{ }^{18}$ who measured the efficiency with which the rare gases at low pressures are excited by protons.

Our overall results are consistent with the kinetic model that predicts that excited xenon atoms and ions are de-excited through the formation of excited 
diatomic molecules which subsequently decay through photon emission. The excited dimers are formed in a three-body reaction; the rate of this reaction should be proportional to $\boldsymbol{P}^{2}$. We observed approximately this pressure dependence in the buildup of $\mathrm{UV}$ emission.

Our results further show that the excited molecules decay radiatively with a mean lifetime of about $2 \times 10^{-8} \mathrm{sec}$. In most of our measurements with the $0.6-\mathrm{MeV}$ electron pulse at pressures greater than $200 \mathrm{psi}$, a very fast UV component - with a mean lifetime on the order of $2 \times 10^{-9} \mathrm{sec}-$ was also present. This component followed the electron excitation pulse. We concluded that it was evidence of stimulated emission.
To support this conclusion, we made additional measurements with the $2 \mathrm{MeV}$ beam using mirrors to form an optical cavity (see Fig. 9). To make aligmment less critical, the mirrors were slightly curved (1-m radius).

In our experiments with the cavity, the previously observed 150- $\AA$-wide emission band centered at $1700 \AA$ narrowed to a sharp emission line about $17 \AA$ wide and centered at $1716 \AA$. This gain narrowing indicates that stimulated emission occurred. Pinhole-camera photographs showed a high-intensity, well-defined be?: $i$ spot along the axis of the optical cavity (perpendicular to the electron beam) and the FWHM of the photodiode output narrowed from $50 \mathrm{nsec}$ to about 3 nsec.

\section{A CYLINDRICAL, RING-ELECTRODE POCKELS CELL FOR ISOLATING}

FAST PUL.SES OF LASER LIGHT

Many laser applications require single, sharp laser-light pulses of very short (subnanosecond) duration. Such pulses can deliver their energy to a target before the energy can be dissipated by explosion or thermal conduction. Electro-optical deviees such as uitrafast Pockels-cell shutters are normally used to extract these short pulses from laser beams. We have developed a Pockels cell that offers an order-of-magnitude improvement in pulse quality over previous designs.

In a Pockels cell, a voltage applied to the crystalline material that makes up the cell will cause the crystal to become birefringent - that is, the crystal will separate an incoming beam of polarized light into two components that propagate with different velocities. The two components recombine in such a manner as to rotate the plane of polarization of the beam as it exits the material. The amount of this rotation depends on the applied voltage. By using a calcite prism or Brawster-angle plate as an analyzer, the rotated beam can be extracted from the rest of the beam. (The analyzer is oriented to pass light whose plane of polarization has been rotated $90^{\circ}$; the Pockels cell is most efficient at this rotation.) Thus, by applying very short, sharp electrical pulses of the proper voltage to a Pockels cell located between a polarizer and an analyzer, one can extract very short, sharp light pulses from a laser beam.

The properties of a Pockels cell that are critical to its performance are the voltage required to produce the $90^{\circ}$ rotation; the uniformity (across the diameter of the light beam) with which the cell transmits and rotates the beam; the losses in the cell due to reflection from the faces, absorption in the crystal, and birefringence due to stress in the crystal; and the speed

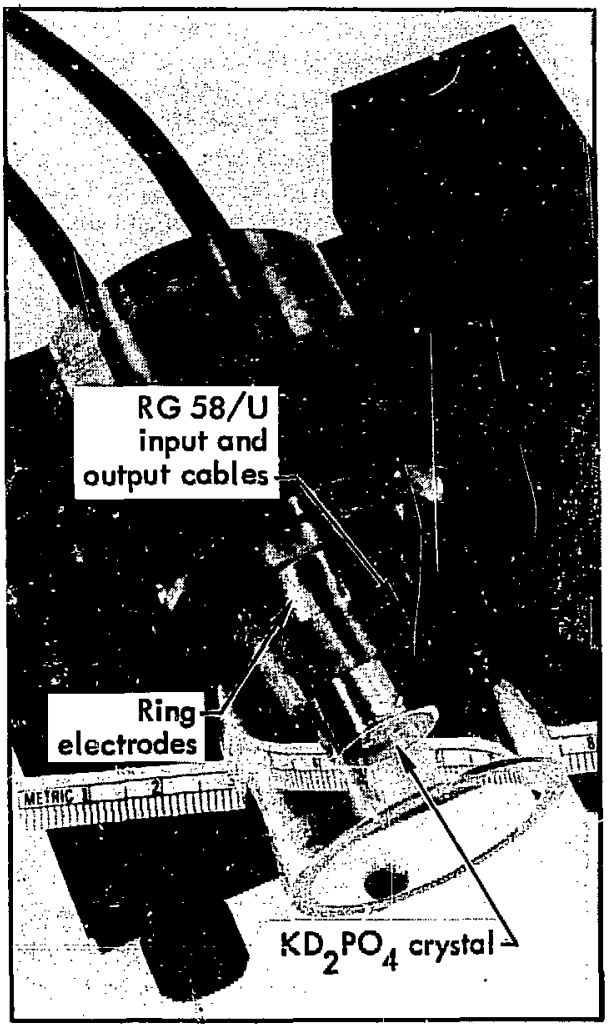

Fig. 11. Cylindrical, Ingelectrode (CRE) Pockels cell inside a Lucite sleeve. The cell is a crystal of $\mathrm{KD}_{2} \mathrm{PO}_{k}$. 
with which the optical signal can be affected, Our efforts to develop an improved Pockels cell were directed specifically toward maximizing the speed of response and minimizing transmission nonuniformities in the cell, while at the same time developing techniques for accurately monitoring the fast light pulses and determining the quality of the cell material.

Our new Pockels cell is made of potassium dideuterium phosphate $\left(\mathrm{KD}_{2} \mathrm{PO}_{4}\right)$. This is the deuterated isomorph of potassium dihydrogen phosphate $\left(\mathrm{KH}_{2} \mathrm{PO}_{4}\right)$, which has been produced commercially since the 1940 's. $\mathrm{KD}_{2} \mathrm{PO}_{4}$ is a uniaxial erystal; i.e., it has only one axis of optical symmetry. When a wave of polarized light from an yttrium-aluminum-garnet (YAG) laser, which has a wavelength of $1.06 \mu \mathrm{m}$, is propagating along this axis, about $10 \mathrm{kV}$ must be applied to the crystal (also along the optical axis) to obtain maximum transmission through an analyzer oriented to pass light rotated $90^{\circ}$ to that entering the crystal.

The crystal is cylindrical, $12 \mathrm{~mm}$ in diameter and $25 \mathrm{~mm}$ long; the axis of the cylinder approximately coincides with the optical axis of the crystal. The two electrodes through which the voltage is applied are 8-mm-wide brass rings placed around the ends of the cylinder (see Fig. 11). The assembly is enclosed in a Lucite sleeve to insulate the cell from air currents and to protect experimenters against the high voltage. This cylindrical, ring-lectrode (CRE) design represents a substantial advance in the technology of Pockels cells with respect to both switching speed and the uniformity of rotation and transmission of light.

In assembling such a cell, one must be careful to avoid straining the crystal, which would alter its optical properties by causing stress birefringence. The electrodes were machined to a tolerance of about 0.001 in. and carefully fitted over the ends of the crystal, and all soldering necessary to attach cables to the elestrodes was done before the electrodes were piaced on the crystal. Having taken these precautions, we found that, after the electrodes were attached, the transmission pattem of the cell between crossed polarizers was identical to that of the original crystal blank.

For the cell to have an optimum time response, the capacitance between the electrodes and the inductance of the cable connecting them must be minimized. The cylindrical electrode geometry represents a minimum-capacitance configuration, and, with the inductance of the connecting cable minimized by placing the exposed cable as close as possible to the surface of the cylinder, the switching speed of the cell is optimal.

The performance of a cell of this kind has been treated theoretically by Vitkov, ${ }^{19}$ who considered a

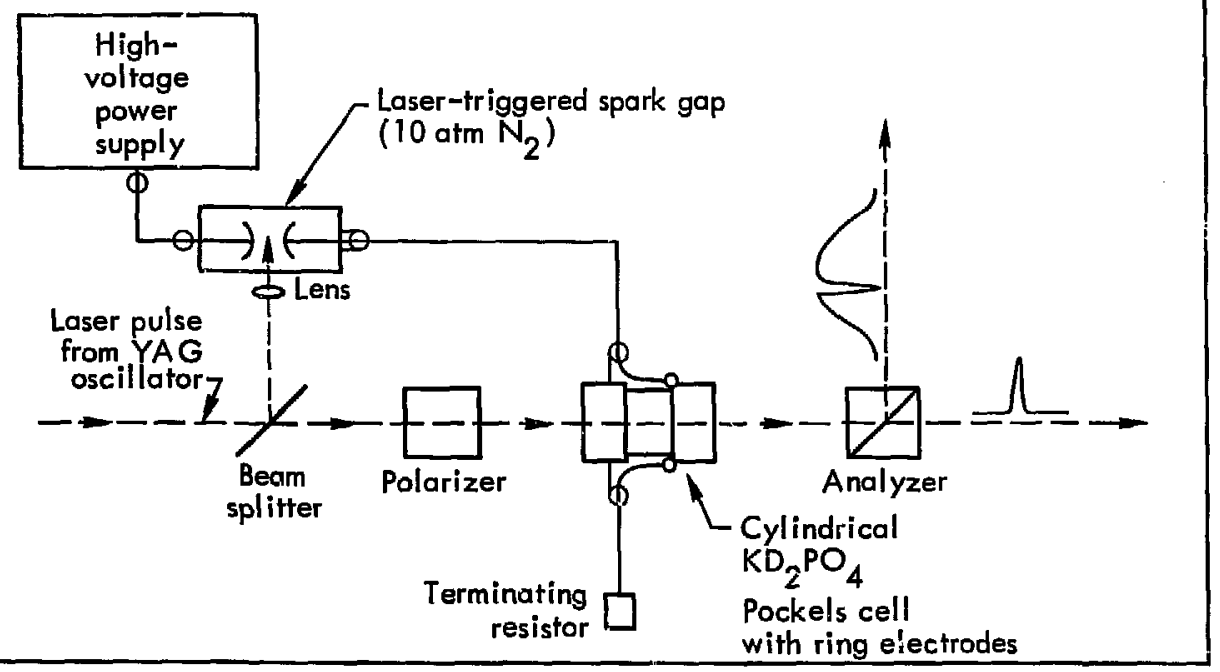

Flg. 12. Experimental amengement for using a fast Pockels cell to obtain subnanosecond laser pulses. The polarizer and the andyzer are crosed $90^{\circ}$ to each other, so that the analyzer passes light only when the Pockels cell is receiving a 10-kV pula from the apark gop, briefly rotating a component of the beam by $90^{\circ}$. The spark gap is triggered by the pule from the laser. The two oscilloscope traces show the pulse exiracted by the Pockels cell and the remainder of the longer pulse generated by the laser. 
rectangular cell with electrodes attached as bands around the ends of the cell. For our cell, conversion of his results to cylindrical coordinates yields a predicted nonuniformity in rotation of about $2.2 \%$ between the center and the edge of the crystal. We have checked this prediction experimentally by placing a CRE cell between polarizers and observing the variation in the voltage required to rotate a light bean $90^{\circ}$. The nonuniformity in rotation was abcut $1.5 \%$, which agrees well with the theoretical prediction. (A rotational nonuniformity in this range implies a $0.02 \%$ nonuniformity in the amount of light transmitted across the aperture of the cell.)

With the same experimental setup, we have also checked the extinction ratio (the ratio of the intensity of light transmitted by the analyzer with the voltage applied to the Pockels cell to that transmitted with the voltage off) over the entire aperture for two different CRE cells. We found it to be greater than 1500:1.
These results represent order-of-magnitude improvements over commercially available $\mathrm{KD}_{2} \mathrm{PO}_{4}$ cells, which typically have rotational nonuniformities of about $13 \%$ and extinction ratios of atout 200:1 over the same aperture.

Figure 12 illustrates the experimental use of a fast Pockels cell for obtaining suonanosecond laser pulses. A 30-nsec pulse is generated by a $Q$-switched YAG laser oscillator. When sufficiently intense light is focused onto the spark gap, it generates an electrical signal of 0.5 -nsec halfwidth, and this signal is impressed across the Pockels cell. An optical signal, whose halfwidth is determined by the response of the Pockels cell to the electrical pulse, is then passed by the analyzer. After corresting the observed optical signal for the response time of the detecting system, we conservatively estimate that the halfwidth of the "chopper" light pulse is less than 0.7 nse We expent that this light pulse can be made evell shorter by shortening the electrical driving pulse.

\section{X-RAY CONVERSION EFFICIENCIES OF LASER-PRODUCED PLASMAS}

A short, high-energy pulse of laser light focused on a target (usually of metal) can convert a small portion of the iarget to a hot, dense plasma that emits $x$ rays. If the process by which laser energy is converted to $x$ rays can be made efficient enough, laser-produced plasmas could be ustful in applications that require a sharp burst of $x$ rays - e.g., flakh $x$-ray photography or simulation of the $x$-ray output of a nuclear explosive.

We have completed a survey of the x-ray yields and conversion efficiencies of plasmas produced when a pulse of light from the Plasma $X$ neodymium-glass infrared laser ${ }^{20}$ is focused on targets of various matcrials. As well as providing information on the possible use of laser-produced plasmas as a source of short-pulse $x$ rays, the results of the survey also provide a test of theoretical calculations haseá on a hydrodynamic radiation code.

The experimental setup is shown schematically in Fig. 13. The energy output of the laser, which was measured by the photodiode, averaged about $2 \mathrm{~J}$, and the pulse width was about 100 psec. The laser beam entered a chamber evacuated to a pressure of about $10^{-4}$ Torr and was focused on a target to a spot about $100 \mu \mathrm{m}$ in diameter.

We considered several different detectors tor measuring the $\mathbf{X}$ radiation enitted by the resulting plasma, including calorimeters, solid-state detectors, and ionization chambers. An ionization chamber was judged to be the most suitable for our purposes because it is easy to calibrate and because its sensitivity in its normal operating region is nearly independent of the energy of the $x$ rays, so that the interpretation of the data obtained does not depend on the energy spectrum of the $x$ rays.

The ionization chamber is a flowing-gas cev' ter (90\% argon, $10 \%$ methane). $\mathrm{X}$ rays enter the chamber through a $1 / 2$-in.-diam window that is offset from the high-voltage electrode in the center of the chamber.

The lower limit of the $x$-ray energies that the counter can respond to is determined by the window material. We used two materials, I-mil-thick Mylar and 0.6-mil-thick beryllium, and made measurements on the various targets with each window. The lowest energies at which these windows transmit at least half of the $\mathrm{x}$ radiation are $1.3 \mathrm{keV}$ for the beryllium and $2.5 \mathrm{keV}$ for the Mylar.

The upper limit of the counter's energy response is determined by its length. We arbitrarily selected a length $(36 \mathrm{~cm})$ that corresponds to two mean free paths for 10-keV $x$ rays in argon; a detector of this length can capture $87 \%$ of the $10-\mathrm{keV} x$ rays.

We calibrated the counter both with a known radiation source, ${ }^{238} \mathrm{Pu}$ ( $\alpha$ particles), and with voltage pulses of known characteristics. Both methods lead us to conclude that the counter's accuracy in terms of absolute charge collection is at least $\pm 10 \%$.

Figure 14 shows our results for the conversion efficiency (the ratio of x-ray energy to laser energy) as a function of the atomic number of the target material. The polyethylene data are plotted at atomic number 3 , which is approximately the average atomic 


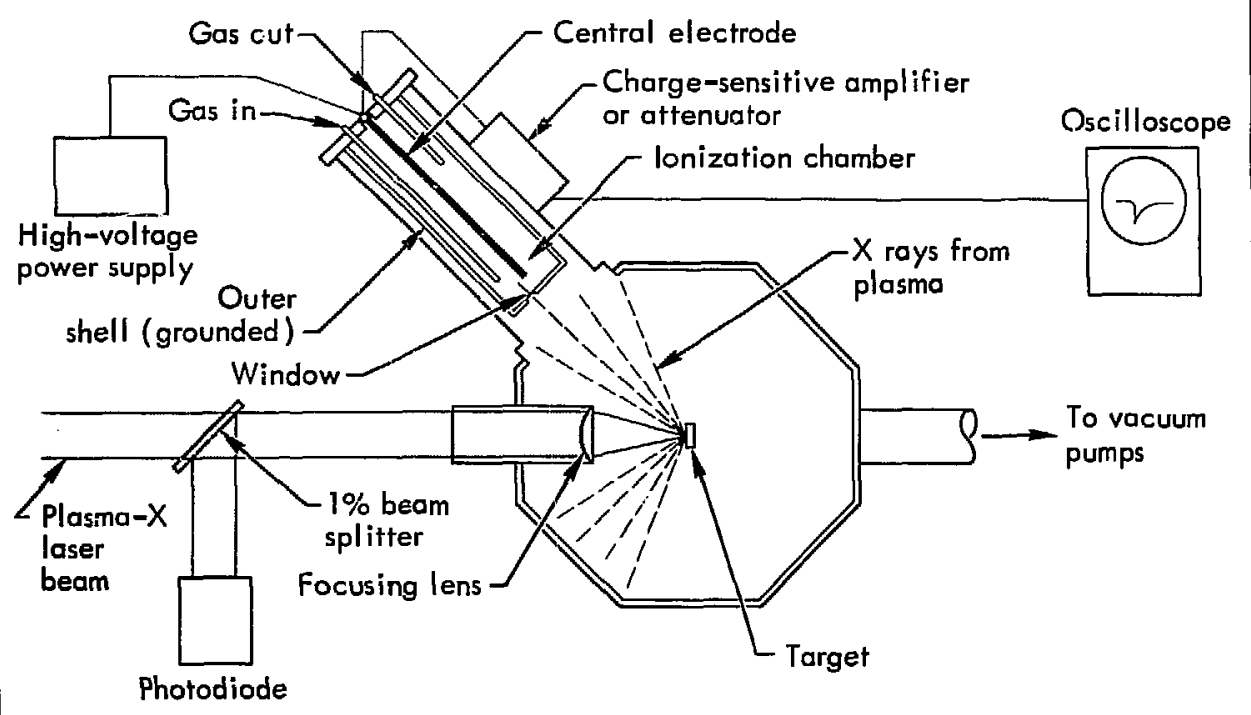

Fig. 13. Experimental arrangament for measuring the x-fay yields and conversion efficiencies of laser-produced plas.nas, The bsic design of the ionization chamber is also shown.

number of $\mathrm{CH}_{2}$. With the high- $Z$ targets (having an atomic number of at least 40) the conversion efficiency is about $10^{-4}$ for the $>2.5-\mathrm{keV} x$ rays that pass through the Mylar window and about $10^{-3}$ for the $>1.3-\mathrm{keV} x$ rays that pass through the beryllium window.

For sulfur $(Z=16)$, this order-of-magnitude difference in conversion efficiency is not observed. This indicates that the sulfur target is emitting relatively few $x$ rays with energies between 1.3 and $2.5 \mathrm{keV}$. The $K \times$ rays of atomic sulfur have energies near $2.4 \mathrm{keV}$ : and the transmissions of these $X$ rays by the two windows actually differ by only about a factor of 2. Thius, the sulfur data suggest that most of the sulfur $X$ rays above $\sim 1.3 \mathrm{keV}$ are emitted in $\boldsymbol{K}$ x-ray lines. The same conclusion can be drawn from the data on aluminum $(Z=13)$, since the ratio of the transmissions of the two window materials for the aluminum atomic $\boldsymbol{K} \times$ rays (having energies of about $1.4 \mathrm{keV}$ ) is roughly the same as the ratio of the aluminum target yields - namely, about a factor of 10 .

Since the $x$-ray line radiation from the carbon and $\mathrm{CH}_{2}$ targets is of too low an energy to pass through either window material, the transmitted radiation must consist of continuum $x$ radiation, which is due to recombination processes or bremsstrahlung or both.
Assuming that the electrons in the plasma have a well-defined temperature, we have inferred temperatures from the carbon and $\mathrm{CH}_{2}$ data of about 0.4 and $0.2 \mathrm{keV}$, respectively.

We used the MONTE-WAZER code to try to theoretically reproduce some of the experimental results. In this code, the populations of the bound states of the target elements are not assumed to be in local thermodynamic equilibrium. This means that both the equation of state and the opacity of the plasma are more complicated than in equilibrium problems.

Our calculations for a gold target, in which it was assumed that all of the laser energy was absorbed by the target, indicated that about $30 \%$ of the energy is emitted from the front surface of the target in the form of $x$ rays. The $x$-ray energy below $1 \mathrm{keV}$ should account for $85 \%$ of the total $x$ rays emitted. In addition, we predicted discrete line radiation at energies of 2.65 and $3.55 \mathrm{keV}$; the line at $2.65 \mathrm{keV}$ should be about five times stronger than the one at $3.55 \mathrm{keV}$. (This agrees fairly well with observations reported previously, which show line radiation at an energy of about $2.4 \mathrm{keV}$. MONTE-WAZER uses an approximate procedure to compute line energies, so the difference between 2.4 and $2.65 \mathrm{keV}$ is not significant.) 
We calculated further that the total energy emitted from the gold target in the form of $>2 \cdot \mathrm{keV} \times$ rays should be $2.6 \%$ of the absorbed laser energy. This result is more than an order of magnitude greater than the value inferred from the $x$-ray yield measurements
(Fig. 14 shows that the conversion efficiency for a gold target with a beryllium window is about 6 $\times 10^{-4}$ ). Additional investigations are being carried out in an attempt to understand the discrepancies between the computed and the experimental results.

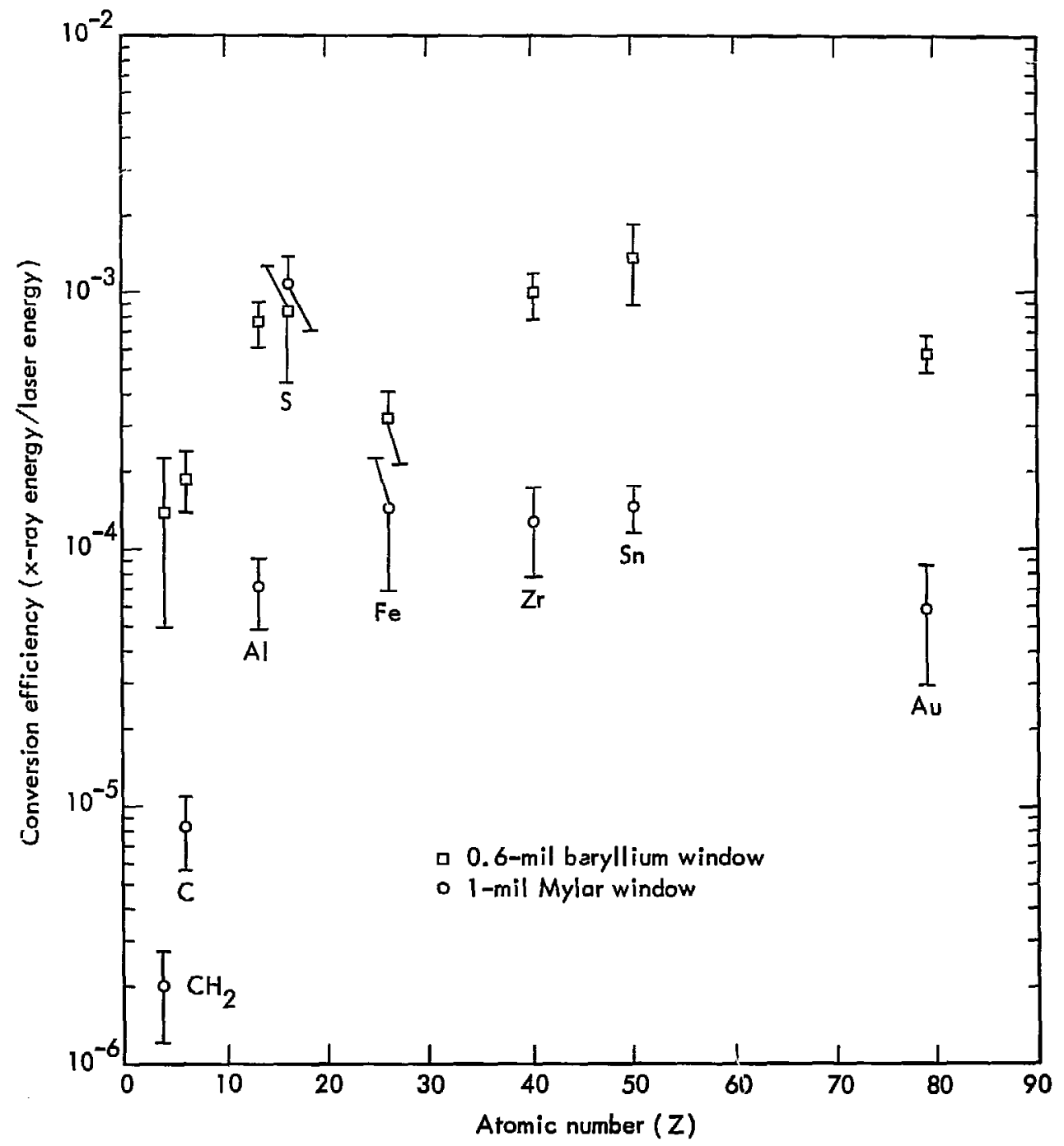

Fig. 14. $X$-ray conversion efficiency of the plasma produced when the Plasma $X$ lnser beam strikes tugets of various atomic numbers, Isotropic $x$-ray emission is assumed. The beryllimm window transmits $x$ rays with energies above $\sim 1.3$ keV; the Mylar window transmiti $x$ rays with energies above $\sim 2.5 \mathrm{keV}$. 
In high-powered, high-gain laser systems, the amplifier stages must be optically isolated from each other and from the target of the laser beam so that spontaneous emission from the amplifier stages and reflections from the target do not travel back through the amplifiers. Inadequate isolation results in depumping in the amplifier chain due to premature lasing (prelasing) and in damage to the laser oscillator and the other optical components due to high-intensity reflections from the target. As part of our continuing investigation of isolators for both gas and solid lasers, we have studied a potential bleachable isolator system based on sulfur hexafluoride $\left(\mathrm{SF}_{6}\right)$ as the saturable absorber for $\mathrm{CO}_{2}$ laser systems, and are building several glass isolators based on the Faraday effect for solid lasers.

\section{Bleachable Isolators for $\mathrm{CO}_{2}$ Lasers}

A bleachable isolator system for $\mathrm{CO}_{2}$ lasers must absorb enough of the low-intensity spontaneous emission at all $\mathrm{CO}_{2}$ lasing frequencies to prevent prelasing in the amplifier chain, and then it must become transparent, or bleach, with minimum consumption of laser energy when the desired high-intensity laser pulse passes through the system. This bleaching occurs when the populations of the upper and lower vibrational-rotational states of the absorber are equal. Absorption and stimulated emission occur at equal rates in such a system; it is transparent at the frequency of the transition between the states. 13

We recently tested a bleachable isolator system that uses $\mathrm{SF}_{6}$ as the saturable isolator and 1,1-dichloro-2,2-difluoroethylene $\left(\mathrm{CF}_{2}=\mathrm{CCl}_{2}\right)$ and dichlorodifluoromethane $\left(\mathrm{CF}_{2} \mathrm{Cl}_{2}\right)$ to absorb those $\mathrm{CO}_{2}$ frequencies not absorbed by the $\mathrm{SF}_{6}$. Finwever, its transmission after bleaching was too low because large amounts of the two nonbleaching absorbers had to be used to sufficiently attenuate (by more than 95\%) all of the $\mathrm{CO}_{2}$ laser lines.

Figure 19 shows the frequencies of the molecular transitions $00^{0} 1 \rightarrow 10^{\circ} 0$ and $00^{\circ} \rightarrow 02^{\circ} 0$ in $\mathrm{CO}_{2}$. These two transitions, at 10.4 and $9.4 \mu \mathrm{m}$, respectively, are the $\mathrm{CO}_{2}$ laser transitions. The high-gain $P$-branch lines of the 10.4 $\mathrm{km}$ band are on the left, with successively lower-gain branches to the right. The figure shows a rotational distribution that

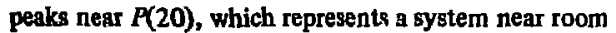
temperature. The intensity distribution is only approximate; it is meant to show all the lines that should be attenuated by the isolator system.

With the exception of heated $\mathrm{CO}_{2}{ }^{14}$ no single gas can be expected to absorb strongly at all $\mathrm{CO}_{2}$ laser frequencies and bleach at the frequenies expected from a mode-locked $\mathrm{CO}_{2}$ laser: the $P(16)$ to $P(22)$ lines, usually $P(18)$ or $P(20)$, of the $10.4-\mu \mathrm{m}$ band. Gases such as $\mathrm{SF}_{6}$, boron trichloride $\left(\mathrm{BCl}_{3}\right)$, phosphorus pentafluoride $\left(\mathrm{PF}_{5}\right)$, vinyl chloride, and propylene absorb and bleach at these frequencies, and many other gases absorb at $\mathrm{CO}_{2}$ laser frequencies and will probably bleach.

We tested an isolator system based on $\mathrm{SF}_{6}$ as the bleachable absorber and $\mathrm{CF}_{2}=\mathrm{CCl}_{2}$ and $\mathrm{CF}_{2} \mathrm{Cl}_{2}$ as "sideband" absorbers. Figure 20 shows the absorptions of these gases in the $\mathrm{CO}_{2}$ laser-line region. The $\mathrm{SF}_{6}$ at 20 Torr-cm (pressure times path length) absorbs from $P(10)$ to $P(30)$ and nearly completely absorbs from $P(12)$ to $P(26)$ of the 10.4- $\mathrm{m}$ band. $\mathrm{CF}_{2} \mathrm{Cl}_{2}$ at 300 Torr-cm absorbs the $P(30)$ and higher $-P$ lines of the 10.4- $\mu \mathrm{m}$ band and the $R$-branch lines of the 9.4- $\mu \mathrm{m}$ band. The 2000 Torr-cm of $\mathrm{CF}_{2}=\mathrm{CCl}_{2}$ absorbs the $\boldsymbol{P}$-branch lines of the $9.4-\mu \mathrm{m}$ band and most of the $R$-branch lines of the 10.4- $\mu \mathrm{m}$ band. To absorb the low $R$ - and $P$-branch lines of the 10.4- $\mu \mathrm{m}$ band, we increased the amount of $\mathrm{CF}_{2}=\mathrm{CCl}_{2}$ to 4000 Torr-cm in our test.

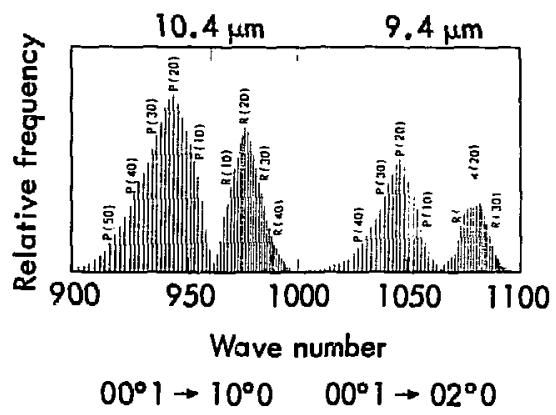

Fig. 19. Frequencies of the $00^{\circ} I \rightarrow 10^{\circ} 0$ and $00^{\circ} 1 \rightarrow 02^{\circ} \mathrm{O}$ transitions in $\mathrm{CO}_{2}$. These are vibration-rotetion tansitions, in which the rotational quantum number $f$ changes by +1 or -1 in going from the initid vibntion-rotation state to the final atate. Tranditions in which $J$ changes by +1 are P-branch lines, and those in which $J$ changes by -1 are $R$-branch lines. 


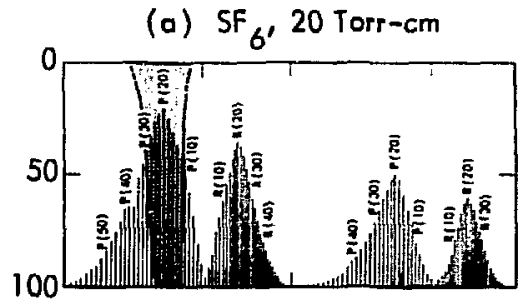

(b) $\mathrm{CF}_{2} \mathrm{Cl}_{2}, 300$ Torr-cm

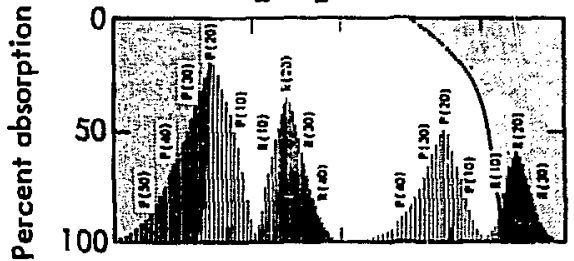

(c) $\mathrm{CF}_{2}=\mathrm{CCl}_{2}, 2000$ Torr $-\mathrm{cm}$

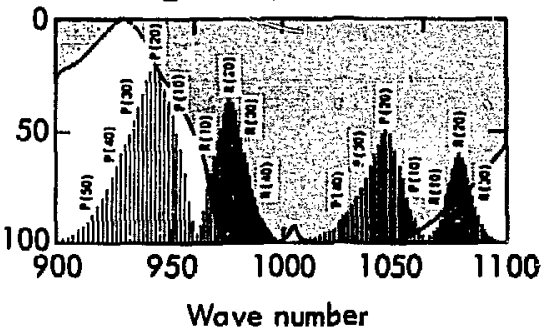

$00^{\circ} 1 \rightarrow 10^{\circ} 0 \quad 00^{\circ} 1 \rightarrow 02^{\circ} 0$

Fig. 20. Absorption of three irolator-syatem gases in the $\mathrm{CO}_{2}$ Inser frequency region.

We tested this system of gases at two laser power levels. To test its transmission at low signal intensities we used a commercial continuous-wave $\mathrm{CO}_{2}$ laser equipped with a grating so that it could be operated on most of the lines shown in Fig. 19. Its output power could be adjusted from 1 to $40 \mathrm{~W}$ for the high-gain lines of each branch, but we generally kept the power below $3 \mathrm{~W}$ when testing low-signal transmission. To test the high-signal transmission we used the LLL TEA laser, 15 which has an oulput power of about $4 \times 10^{6} \mathrm{~W} / \mathrm{cm}^{2}$. We examined the output of the TEA loser with a monochromalor and found that more than $90 \%$ of the laser output energy occurred at the $P(16), P(18), P(20)$, and $P(22)$ lines mear $10.6 \mu \mathrm{m}$.

The absorber cells are $20 \mathrm{~cm}$ long and have $\mathrm{NaCl}$ Brewster-angle windows and a side-arm trap for freczing out the absorber gas. We determine the transmittance of the system with all gases temoved and with any combination of the gases in the laser beam.

The test gas system at low signal intensity absorbed all of the $\mathrm{CO}_{2}$ lines excepl about 2 to $3 \%$ of the $F(6)$ to $P(10)$ lines of the $10.4-\mu m$ band. With the high-intensity fulse, the transmistion of this system was only 35\%; with the $\mathrm{SF}_{6}$ removed it was still only 37\%. We obtained approximately the sume transmission (with the $\mathrm{SF}_{6}$ removed) at the $\boldsymbol{F}(18)$ line with the low-power laser. The transmission of each of the individual gases for the high-intensity pulse wh $94 \%$ for $\mathrm{SF}_{6}, 94 \%$ for $\mathrm{CF}_{2} \mathrm{Cl}_{2}$, and $40 \% \mathrm{for}$ $\mathrm{CF}_{2}=\mathrm{CCi}_{2}$. The accuracy of this Iransmission data is about $\pm 2 \%$.

The transmission of the system for the high-power pulse could be increased to nearly the value of the $\mathrm{SF}_{6}$ alone by reducing the amount of the other absorbers, especially the $\mathrm{CF}_{2}=\mathrm{CCl}_{2}$. However, this would increase the low-power transmistion of the low $P$. and Rbranch lines of the $10.4 \mathrm{~km}$ band to nearly IOU\%. Compounds with absorption bands centered near $10.4 \mathrm{fm}$ could attenuate these lines; we are now evaluating $\mathrm{CH}_{3} \mathrm{CF}_{3}$ and $\mathrm{CF}_{3} \mathrm{CF}_{2} \mathrm{Cl}$.

The narrow width of the $\mathrm{SF}_{6}$ absorption band (about $10 \mathrm{~cm}^{-1}$ at 20 Torr-em) is the major problem of the system. Most infrared bands do nor have tharp absorption edges, and finding compounds to precisty natch the areas of $\mathrm{CO}_{2}$ emission nol absorbed by $\mathrm{SF}_{6}$ is difficult. A better solution would be 10 use a sarurable absorber gas that absorbed all or nearly all of the Pbranch lines of the $10.4 \mu \mathrm{m}$ band and possibly some of the $R$-branch lints. Both $\mathrm{BCl}_{3}$ and $\mathrm{PF}_{5}$ have wider bandwidths than $\mathrm{SF}_{6}$. The $\mathrm{PF}_{5}$ absorption maximum is centered near the $P(20)$ line, while $\mathrm{BCl}_{3}$ has a band from $\mathrm{II}_{\mathrm{BCl}}$ (which constitutes about $81 \%$ of $\mathrm{BCl}_{3}$ ) that absorbs the P.branch lines and a band from ${ }^{10} \mathrm{BCl}_{3}$ (about $19 \%$ of $\mathrm{BCl}_{3}$ ) that absorbs the R-branch lines. We will study systems based on these two compounds and on other saturable absorbers with brond bands.

\section{Fanday Isolator for Gles Laes}

Our elforts on isolators for solid lasers are concentrated on investigating and applying highdurability materials for Faradayeffect isolators. We then design the hardware for providing the masnetic field to complement this material.

In a Faradayeffect material, magnetic field induces a zolation of the optical plane of polarization. This rotation is proportional to the Verdett constant (rotation per unit path length and field streng(h) of the material, the magnitude of the magnetic field, and the length of the material in the magretic field. Als to be considered in the design of Faraday isolators are 
the optical demse threthnd and the optial distortion of the material.

Our pretenl efforts ate directed toward twolators of three aperure diametert: 16, 25, and $50 \mathrm{~mm}(70 \mathrm{~mm}$ commercial units are avilable but afe very expensive). For the $16 \mathrm{tmm}$ tize we have found that the prestefly

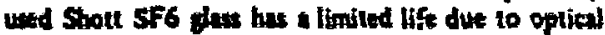

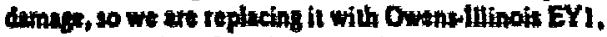
a later fins doped with $40 \%$ lerbium. For both the 25-me rotator, which is alredy bull, and the 50mm

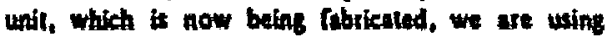

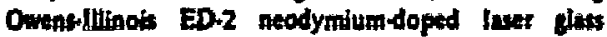
becaus, in addition to its fith optien quatily, it has the ane donst throthold a the laser ampilfer rods. Howner, this mutortal has low Verdat contunl (0.00is to $0.005 \mathrm{~min} / 0 \mathrm{ecm})$ and contratuatly roputres mapete folds in the fens-oftllogint range for a length of $15010200 \mathrm{~mm}$. Although this length of glus in the beam path could be delrimental (because nonlinear effects such as self.focusing can occur). we prefer the ED-2 olas to materials that have higher Verdett constants but lower durability.

Implicil in the dusign of high-quatly Fraduy bolators is the detign of arilability of high-quality polarizetenslyzer units. We have used commetcially miliable cleicic and quant prims, but caloite protins we nol whituble for aperture dianeters hrger than about $25 \mathrm{~mm}$ and quare pritms give insulficiont agular dberimination when the ditunce between the bolator and the amplititi is lest than about $10 \mathrm{ft}$. Therefore, we art investigating alums. tive polarizing techniques such as stecked dass. plate polutizes, which have been used at other Liboratotics. 
Experiments by Slamper et al. ${ }^{27}$ have shown that large magrelic fields sre generated in laser-heated plasmas by thermoelectric effects. Now we have demonstraled with computer calculations that inclusion of these mugnetic fields is important in obsining realistif predictions of neutron production from the plasma.

Using MOKU, ${ }^{20}$ an Eulerian two-dimensional magnetohydrodynamic explosion code, we calculated the netition production from a nat solld-deuterium target healed by a laser beam. 29 In one set of calculations the thernioelectric source of magnetic fields was nol included, and in another set it was included. The calculations without magnetic field gave a neutron production some three orders of magnitude lowet than experimental results, while the calculations with magnetic field agieed well with experiment.

For both sets of calculations we assumed a laser pulse with a colal energy of $80 \mathrm{~J}$, a pulse length of 4 nsec, a beam radius of $50 \mu \mathrm{m}$, and a wavelength of $1.06 \mathrm{\mu m}$. The target was a diak of solid deuterium $0.04 \mathrm{~cm}$ thick and $0.2 \mathrm{~cm}$ in diameter (see Fig. 9).

We astumed that the absorption br the laser light by the platm occurted though invero bremsinhlung (collsional ibsorption), and we forrected for IWo-tream plasm instrbility, a type fof anomalous (collsioniess) absorption. 30 ye also appited a similar correction to other plasma-trayport coefficients, such

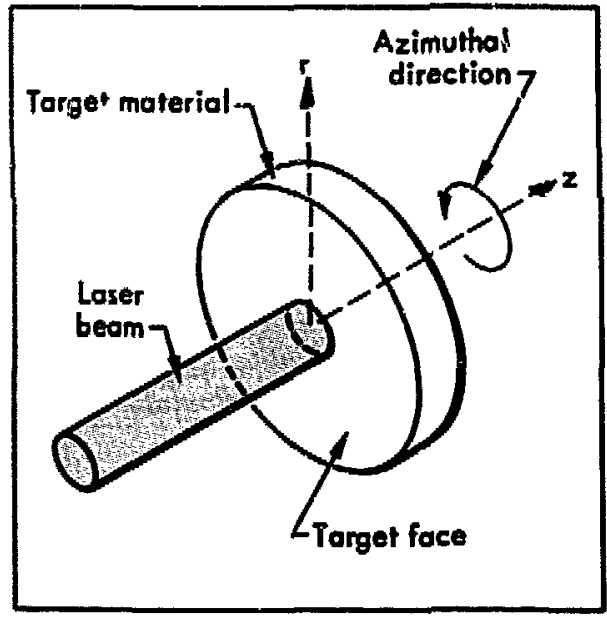

Fig 9. Asomed tase and angel confaration. as those determining the rate of thermal conduction by electrons. Since the physics of the anomalous absorption is not well understood, we treated the magnitude of this correction as an adjustable parameter.

The production of neutrons in the absence of magnetic fields can be described as follows. As the laser pulse begins to propagate into the target, its energy is absorbed by the electrons near the surface. Because electrons are good thermal conductors, this energy is rapidly transported away from the region of absorption, resulting in rather low peak electron temperatures (less then $1 \mathrm{keV}$ ). Figure 10 shows the lines of conslant temperature and derisity for a typical problem.

Without magnetic fields the peak temperatures occur in material of such low density that the rate at which energy is exchanged between electrons and ions is also low, leading to maximum ion temperatures of less than $0.5 \mathrm{keV}$. Consequently $\mathrm{s}_{\mathrm{s}}$ the production of neutrons by the $\mathbf{D}+\mathrm{D} \rightarrow \mathrm{n}+{ }^{3}$ He reaction, which depends strongly on the ion temperature, is also very small. Depending on the size of the anomalous absorption correction, we obtained total neutron yields in the ringe of 100 to 500 .

For problems in which the thermoelectric generation of magnetic fields is included we obtained the following results. Initially the behavior is similar to that of the nonmagnetic problem: the laser energy is absorbed near the target surface by electrons that are consequently heated and thus try to expand. This leads to density gradients along the z-axis (see Fig. 9) and temperature gradients in the radial (r) direction. Consequently, a magnetic field proportional to the cross product of the temperature and density gradients is created in the azimuthal direction (around the zaivis). Computed mpgnetic field strengths range from 1 to 10 MG.

In contrast to the nonmagnetic case, with the magnetic field the electrons cannot conduct heat across fisld lines. Thus, heating of the material occurs only in the region of the beam. The result is a flow of electrons out of the target along the z-axis, lowering the density at the target surface and allowing the laser beam to penetrate further into the target, boring a hole in it. The electrons and ions become very hot near the deep end of the hoie, where the heat loss rate is low, resulting in a substantial production of neutrons (see Fig. 11).

In general, we found that the production of neutrons is a very sensitive function of the anomalous 


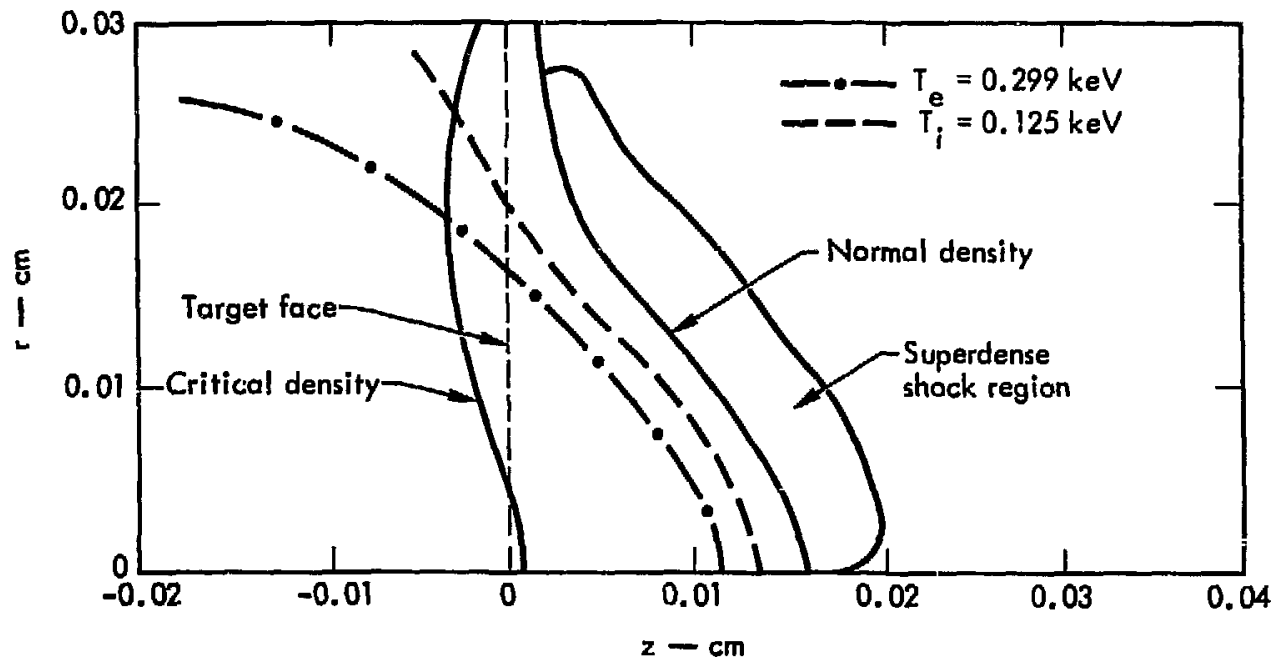

Fig. 10. Dendity and temperature contoun 2.13 nsec ster a laser beam has struck the target - magnetic fields not included. The density contours indiente where the density equils the normal density of the tagat and where it equals the critical dendty (the dendity at which the piama frequency equals the liser frequency). Lines of constant electron temperature $\left(T_{f}\right)$ and ion temperature $\left(T_{p}\right)$ are also shown; muximum values of $T_{e}$ and $T_{1}$ in the problem wenc 0.828 and 0.352 keV. The dense thock region created by the exponding plasm is indicaled.

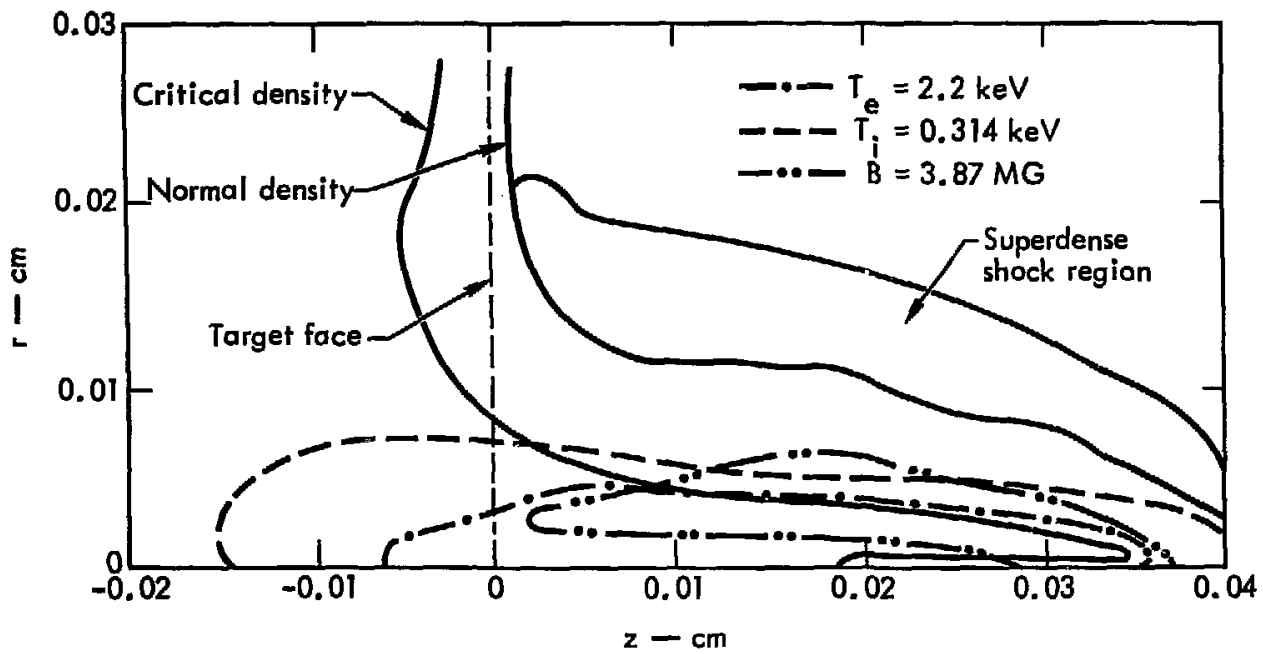

Fig. 11. Density and temperature contours 2.08 nsec after a laser beam has struck the target - magnetic stelds included. Contours of denaity, electron ond ion temperature, and magnetic field $(B)$ are shown; maximum values of $T_{e}, T_{p}$ and $B$ in the problem were $15.0 \mathrm{keV}, 1.9 \mathrm{keV}$, and $8.7 \mathrm{MG}$.

absorption correction and of the assumptions made concerning the behavior of laser light near the critical depth in the plasma (where the plasma and laser frequencies are equal). Depending on the values chosen for these parameters, the nautron yields we obtained ranged from about $10^{3}$ to $3 \times 10^{4}$; the upper end of this range is in good agreernent with experimental results. ${ }^{31}$ 
In summary, our calculation without magnetic fields gave neutron yields on the order of a few hundred neutrons, and this yield was relatively insensitive to the details of the calculation. With magnetic fields the yield was increased by a factor ranging from 10 to 1000 and was very sensitive to the assumed problem parameters. Although the good agreement between the experiment and some of the problems including the magnetic field may be partially fortuitous, it seems clear that the inclusion of such fields will be necessary in understanding the physics of laser-heated plasmas.

\section{A NEW APPROACH FOR DEMONSTRATING THE FEABIBILITY OF EFFICIENT PULSED CHEMICAL LASERS}

We have developed an experimental method that appears to be the simplest and fastest way to search for the branched-chain chemical reactions that may be essential for a highefficiency pulsed chemical laser. With it we hope to demonstrate that such lasers are feasible. The method is based on a form of initiation designed to separate two important functions: (1) transformation of the stable premixed chemicals to a "critical" state where branched chain reactions can occur, and (2) pruduction of a suitably intense and appropriately timed uniform supply of radicals in the mixture to initiate the reactions. We produce the critical state by using a pulsed $\mathrm{CO}_{2}$ laser to rapidly preheat the chemical mixture through vibrational-to-translational enesgy transfer, then we produce the supply of radicals to initiate the branched chain reactions by an electric discharge. The apparatus can also be used to search for chemical laser action

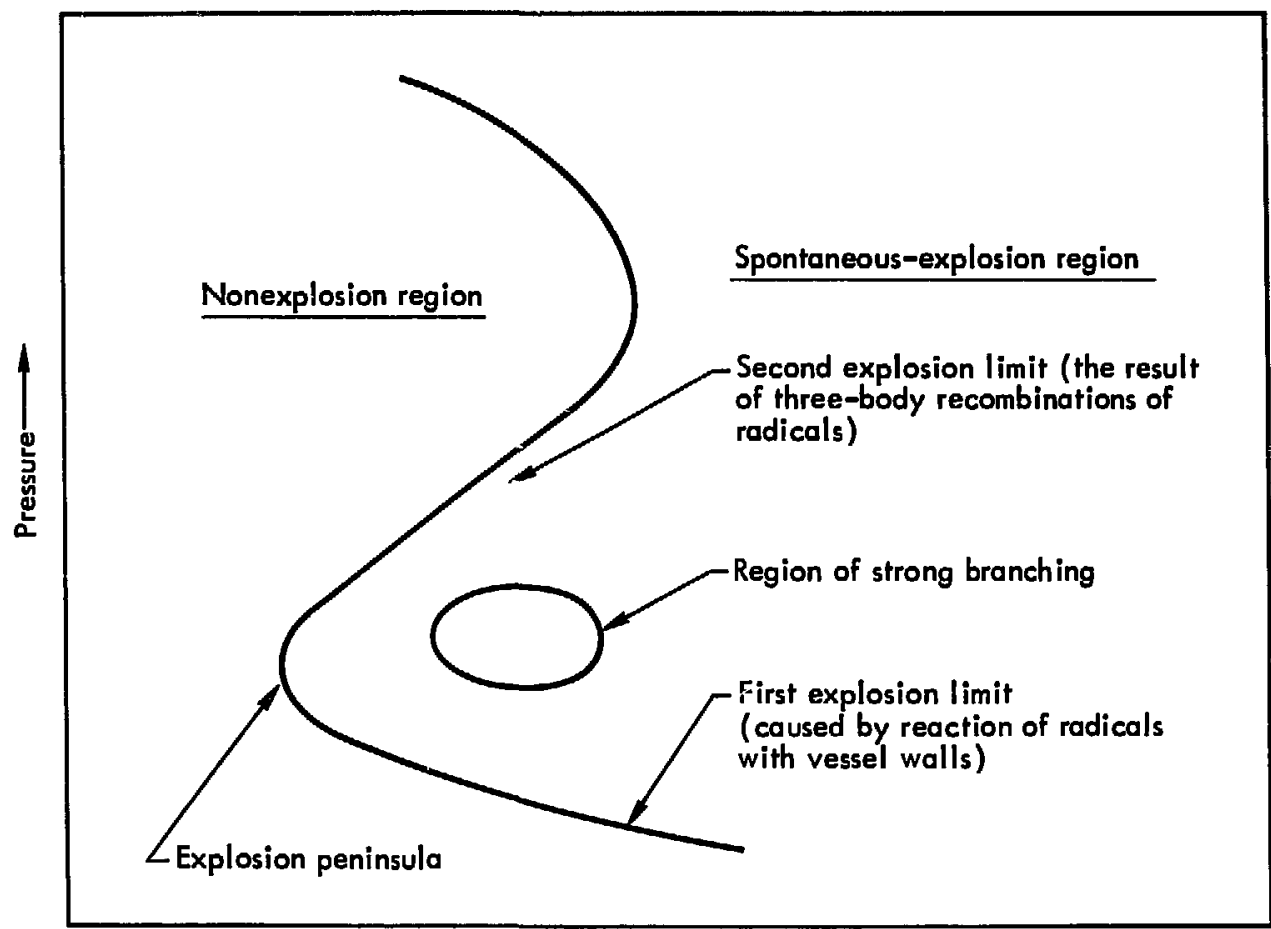

Temperature $\longrightarrow$

Fig. 12. Prescure-temperature diagram for a spontaneously exploding gas, In the region of atrong branching, chemical reactions readily occur that multiply the number of free radicals and thus increase the number of molecules in excited atates that are responsibie for laser action. 
induced solely by the $\mathrm{CO}_{2}$ laser, and to study the temperature dependence of some chemical laser systems.

\section{Backround}

The efficient pulsed chemical laser is normally envisioned by reference to an "explosion-peninsula" diagram for a spontaneously expluding gas mixture that exhubits branched chain reactions (see Fig. 12). Such a diagram indicates regions of stability and spontaneous explosion for chemical mixtures as a function of the pressure, iemperature, and (implicilly) the relative concentration of reactants. Scveral Russian scientists ${ }^{32}$ have proposed that within the ignition region there may be an island or zone of brarching chain reaclions that produce laser inversion. The objective in the development of an efficient pulsed chemical laser is to be able to premix reaction gases in a stable pressure, temperature, and concentration region and then provide, at will, a weak uniform source of initiation radicals to drive the mixture nto the desired zone of branched reaction. For the laser to be compact and yet be capable of high power output it is also desirable to be able to use pressures of at least I atm. UnTortunately, no one to our knowledge has yet achieved these objectives.

In our sarly work on the initiation of IF $_{\mathbf{7}} \cdot \mathrm{H}_{2}$ mixtures with a 3-nsec electron beam we reported that the output and pulse width of the laser energy depended on the pressure. ${ }^{33}$ The energy output did not steadily increase with pressure but instead reached a maximum at about 125 Torr with a maximum energy density of about $8 \mathrm{~J} /$ liter. This observation emphasized for the first time that simply increasing the pressure would not necessarily produce the desired high power and high energy density in pulsed HF systems. Furthermore, the output pulse widths decreased rapidly to about 200 nsec near and above the pressure for optimum outpus energy. Other HF-producing systems show similar behavior. ${ }^{34}$ Because of the relatively long electronic-to-kinetic energy transfer times and also the low thermal equivalent of the initiation energy $\left(\sim 10^{\circ} \mathrm{K}\right)$ we do not belleve the gas reached the spontanecus explosion region in Fig. 12 before termination of the laser pulse. We conclude that the laser output was primarily the result of the radicals produced by the electron beam initiation, which reacted to form excited HF. Thus our initiation method did not stimulate the fast, inversion-producing, branched chain reaction that is theoretically required to overcome the detrimental effects of collisional relaxation and three-body recombination.

Since many chemical systems and initial pressuretemperature-composition conditions had been tried using a variety of initiation methods (flashlamps, electric discharges, electron beams) with no evidence of a contribution from branched chain reactions, we questioned the adequacy of conventional initiation techniques. Most such techniques utilize the heat of reaction to drive the mixture into the explosion region, and they start the formation of radicals in an environrnent which, by virtue of its stability, must inherently quench any chain reactions. Hence, the progress of the pressure-temperature coordinates toward the ignition region is probably slow (thermal) and entails undesirable side effects prior to the branched-chain part of the reaction. Such side effects include buildup of a thermal distribution of the vibrational states of HF (which reduces the population inversion required for lasing), buildup of additional collisional quenching species, and depletion of the reaciants.

We considered several ways of shifting the pressure-temperature-concentration coordinates rapidly into the region of fast branched reaction prior to the formation of a sizable quantity of radicals for uniform initation. These included rapid adiabatic compression, microwave heating, shock tube tochniques, bleachable inhibitors, and preheating by laser stimulation of vibrational-to-translational or rotational-to-translational energy transier. We chose to pursue the vibrational-to-translational preheating approash because the short (microsecond) vibrational-to-translational relaxation times and the avallability of high-power $\mathrm{CO}_{2}$ laser radiation offer the possibility of producing significant and rapid changes in the pressure-temperature coordinates prior to initiation by conventional discharge or flash photolysis. Furthemore, this technique is applicable directly to gases that absorb $\mathrm{CO}_{2}$ laser wavelengths $(10.6 \mathrm{~mm})$ and can be extended to any gas mixture by doping it with small amounts $\left(10-20 \%\right.$, say) of materials such as $\mathrm{SF}_{6}$, which strongly absorb near $10.6 \mu \mathrm{m}$. in this manner we can in microsecond risetimes achieve temperature jumps of at least a few hundred degrees Kelvin.

\section{Experimental Apparatus}

Figure 13 is a schematic diagram of our apparatus for preheating gas mixtures prior to dischirge. Essentially, it consists of a double-discharge $\mathrm{CO}_{2}$ laser $^{35}$ whose output is directed into the side of a chemical laser cell through a $\mathrm{NaCl}$ window. The $\mathrm{CO}_{2}$ laser can produce up to $90 \mathrm{~J}$ in about $1 \mu$ sec over a 5-by-12-cm aperture. An electrical pin discharge for initiating the chemical laser can be fired at any time between $6 \mu \mathrm{sec}$ before and $100 \mathrm{msec}$ after the $\mathrm{CO}_{2}$ laser is fired. This pin discharge provides $20-10-100-k e V$ pulses with durations of less than 80 nsec.

Diagnostic equipment at present includes a photomultiplier for monitoring visible and near-uv 


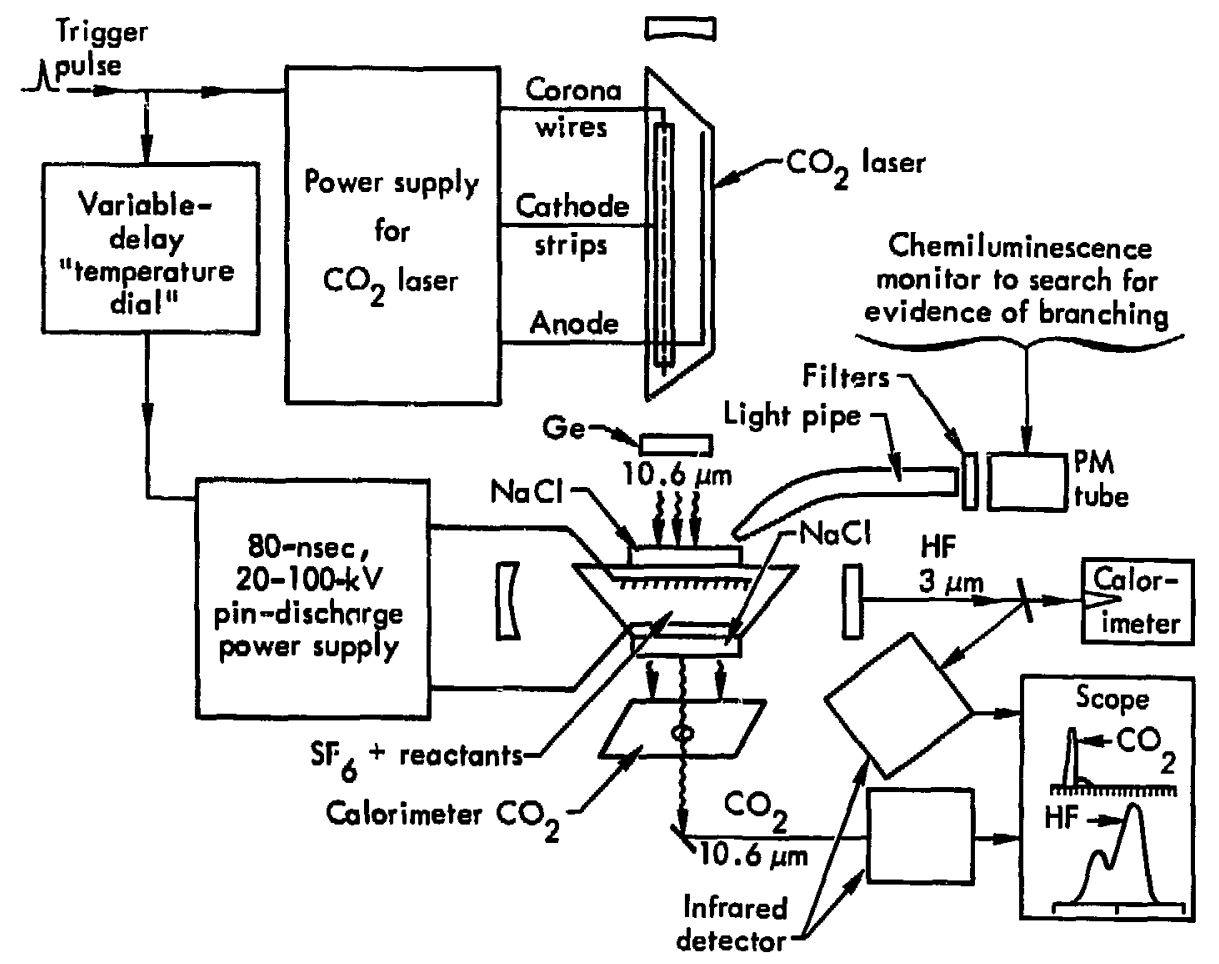

Fig. 13. Scismatic diegrom of the oxperimental chemical-laser appuratus in which a $\mathrm{CO}$, laser is used for preheating the gas missure before tiucharge.

chemiluminescence, calorimeters to monitor the chemical-laser output energy and the $\mathrm{CO}_{2}$-laser radiation transmitted through the chemical laser cell, $\mathrm{Ge}(\mathrm{Au})$ detectors to monitor the pulse shapes and timing of the two lasers, and current-voltage monltoring of the pin discharge. Within the next few months we hope to do time-resolved spectroscopy on the chemical laser output and the chemiluminescence. Also, we are designing a new chemical laser cell that can operate at pressures up to 1 atm. Shock-wave breakage of Brewster-angle windows now limits the cell to pressures of about 50 Torr.

\section{Experimental Results}

Using this equipment we studied $\mathrm{NF}_{3}-\mathrm{H}_{2}-\mathrm{SF}_{6}$ mixtures at 25 Torr, which would explode on unfocused $\mathrm{CO}_{2}$ irradiation alone. For the mixture ratios studied, the overall energy output always decreases as the delay between preheat and discharge is increased (see Fig. 14). Despite this degradation of overall laser output, we have observed some HF laser pulse shapes that seem to indicate an enhancement in the power of the first transition to lase for preheat delays of about $10 \mu \mathrm{sec}$ (see Fig. 15). We have nct yet had a chance to do monochromator measurements to check the lasing transition sequence, so this inference is tentative.

Our data on $\mathrm{N}_{2} \mathrm{~F}_{4}-\mathrm{H}_{2}$ mixtures at 25 Torr, which would not explode on $\mathrm{CO}_{2}$ laser irradiation alone, are shown in Fig. 16. These mixtures varied only in the small amount of cis-2-butene added to inhibit spontaneous explosion during mixing and preshot storage. The bumps and dips in Fig. 16 presumably indicate vibrational energy transfer processes and dissociation in $\mathrm{N}_{2} \mathrm{~F}_{4}$. The eventual approach to the discharge-only (no preheating) output level indicates that the system retums to the initial pressuretemperature conditions without explosion. 


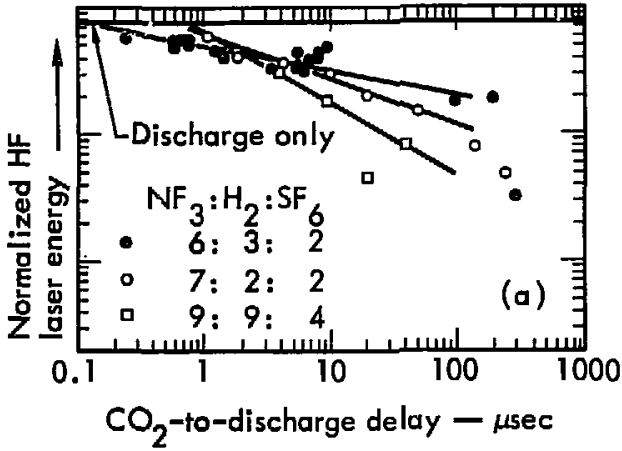

Fig. 14. Dependence of the HF laser energy output on the prehent-to-discharge delay time for various $\mathrm{NF}_{2}-\mathrm{H}_{2}-\mathrm{SE}_{\text {s }}$ mixtures. The temperature of the gas mixture at the time of the discharge increases with the time delay (for delays up to a few hundred microseconds).

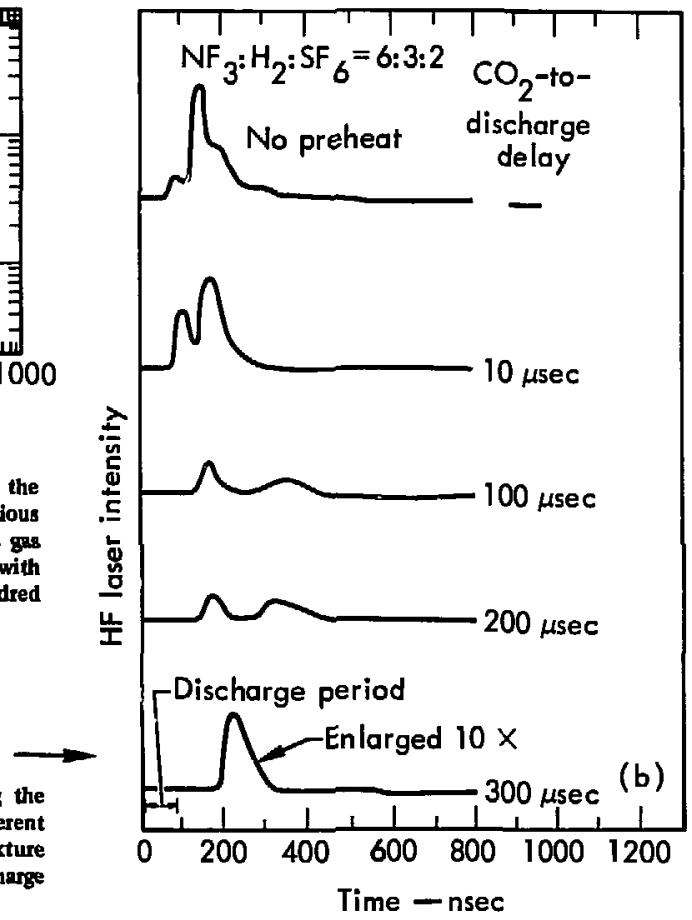

Fig. 15. A sequence of HF-laser pulse shapes showing the effect of $\mathrm{CO}_{2}$ laser preheating for different $\mathrm{CO}_{2}$-to-discherge delay times. The laser gas mixture is 6:3:2 $\mathrm{NF}_{3}: \mathrm{H}_{2}: \mathrm{SF}_{8}$ at 25 Torr. The discharge itself lasts about 80 nsec.

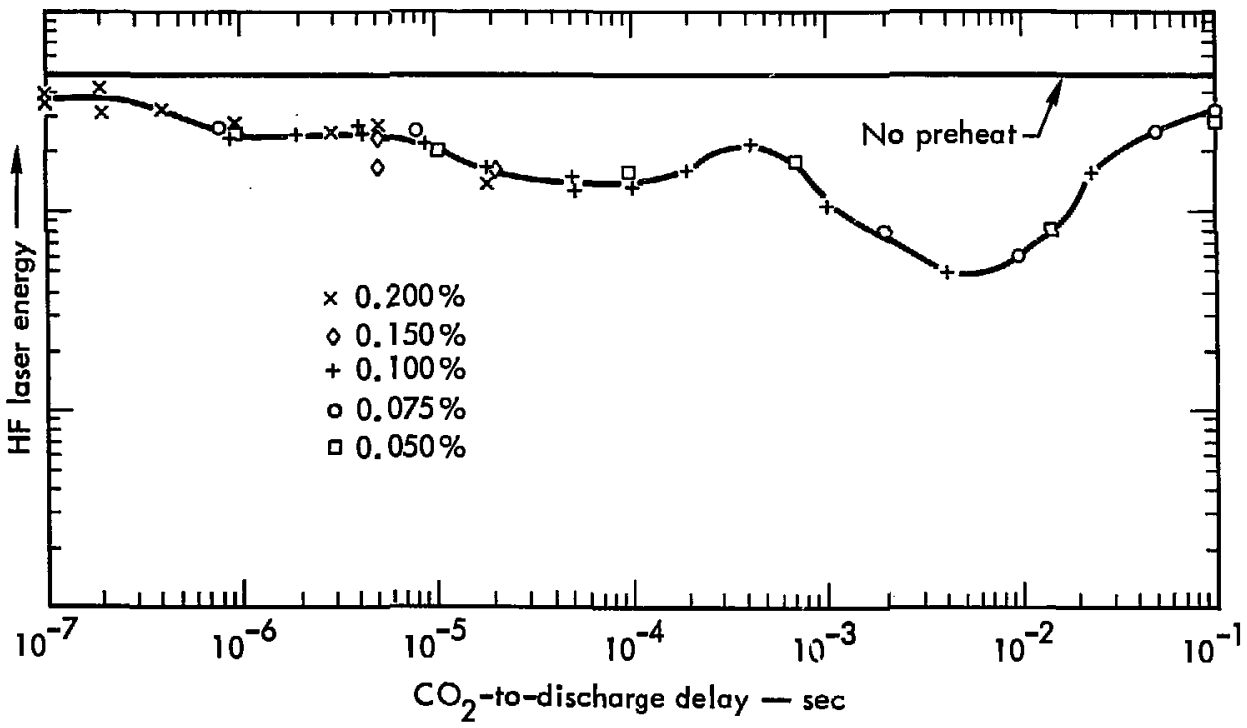

Fig. 16. HF laser output energy vs preheat-to-discharge delay time for a 75:25 $\mathrm{N}_{2} \mathrm{~F}_{4}: \mathrm{H}_{2}$ mixture at 25 Torn, for various amounts of cis-2-butene spontaneous-explosion inhibitor. 
In addition to the preheating experiments just described, we also look for chemical laser action initiated by the $\mathrm{CO}_{2}$ laser radiation alone. Such a discovery would be exciting because it might lead to improvement of overall chemical-laser efficiency and allow conversion to other wavelengths. In our investigations thus far we have not observed any initiation of HF chemical-laser oscillation by the $\mathrm{CO}_{2}$ laser, although the $\mathrm{CO}_{2}$ radiation is capable of inducing explosions in some of the reactive mixtures. This was true even for $\mathrm{N}_{2} \mathrm{~F}_{4}-\mathrm{H}_{2}$, for whici there was an early unpublished claim 36 that laser action had been

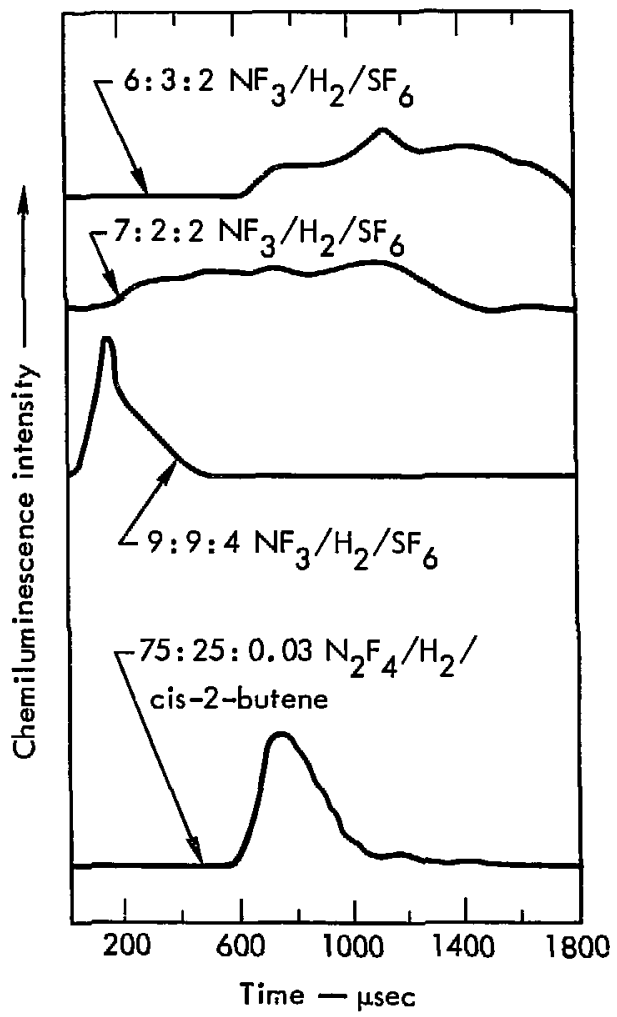

Fig. 17. Time-dependent chemiluminescence data for some $\mathrm{CO}_{2}$ taser-initiated explosions (no pin discharge) at 25 Tort. observed. Subsequently we learned ${ }^{37}$ that the observation had consisted of weak, and possibly questionable, amplification of a probe laser beam.

An important aspect of the $\mathrm{CO}_{2}$-initiated explosions is the time development of the chemiluminescence. By this measurement we hope to be able to observe the presence of a fast branched-chain reaction independent of any enhancement of the laser output; the more chain branching that is occurring, the sooner will chemiluminescence appear. Figure 17 shows the time of onset of chemiluminescence in various mixtures containing $\mathrm{NF}_{3}$ or $\mathrm{N}_{2} \mathrm{~F}_{4}$. The chemiluminescence appears sooner for $\mathrm{NF}_{3} / \mathrm{H}_{2}$ ratios of 1 and 3.5 than for a ratio of 2 .

Referring to Fig. 14, one can see that the faster the quenching speed, the earlier the chemiluminescence appears. This behavior would be expected for thermal explosions. It is also noteworthy that the laser output is quenched before the chemiluminescence appears; however, until we do some spectroscopy we cannot infer with certainty that the HF-producing reactions are taking place at the same rate or at the same time as the chemiluminescence is being emitted.

\section{Conclusion}

In summary, we have developed a versatile experinental system to (1) search for branched-chain reactions which could contribute importantly to the output of chemical lasers, (2) search for chemical-laser action initiated by a $\mathrm{CO}_{2}$ laser, and (3) study the temperature dependence of pulsed chemical-laser systems.

Our initial results with $\mathrm{NF}_{3}-\mathrm{H}_{2}-\mathrm{SF}_{6}$ and $\mathrm{N}_{2} \mathrm{~F}_{4}-\mathrm{H}_{2}$ mixtures at 25 Torr show that the overall energy output decreases as the temperature is raised above $20^{\circ} \mathrm{C}$, which indicates that themal reactions, rather than branched chain reactions, are occurring. Tentatively, it appears that the first transitions to lase can be somewhat enhanced by preheating. We have not yet seen any chemical laser action initiated purely by the $\mathrm{CO}_{2}$ laser, which is not surprising in view of the slow buildup of chemiluminescence.

Our main conclusion is that the techniques we have develnped are the simplest and fastest way to search for brantched chain reactions contributing to laser output and to demonstrate that efficient pulsed chemical lasers are feasible. We will continue to investigate more promising chemical systems. 
The output of one of our lasers, the Short Path Laser, has been limited to unacceptably low intensities due to self-focusing damage in the Nd:glass amplifier rods. Experiments on this laser have demonstrated that the self-focusing in high-peak-power lasers is governed mainly by incidental and of ten unavoidable oiffraction effects or transverse-mode perturbations. Thus, bulk rod damage occurs at power levels well below that at which large-scale self-focusing of the entire beam occurs. We have quantitatively corroborated these experimental observations by computer calculations.

\section{Experimental}

The Short Path Laser consists of a mode-locked Nd:glass oscillator, a single-pulse switchout, and a rod amplifier chain (see Fig. 17). The oscillator provides 15-psec pulses with bandwidths of about $50 \AA$. The detailed structure of these pulses is not known.

Following a 1/2-in. "preamplifier," a lens-pinholelens spatial filter gives a diffraction-limited, spatially smooth beam that is expanded from the $4 \cdot \mathrm{mm}$ oscillator output to about $1.3 \mathrm{~cm}$. An aperture after the spatial filter may be used to restrict the beam entering the next $1 / 2$-in. amplifier, which is $108 \mathrm{~cm}$ from the aperture. This amplifier is followed by two more each separated by $19 \mathrm{~cm}$. Each amplifier is pumped with up to $12 \mathrm{~kJ}$ and gives a small-signal gain of about 10. The system is capable of about $2 J$ out of the 1/2-in. chain, in a nearly diffraction-limited beam.

When we fire about 50 shots, all less than $0.5 \mathrm{~J}$, using the 1/2-in. chain, the last 1/2-in. laser rod is severely damaged. The damage takes the form of a Fresnel diffraction pattern, which results from the aperture following the spatial filter. Careful inspection reveals that the ring pattern is composed of straight trains of damage sites that begin $8 \mathrm{~cm}$ in from the exit face and become more numerous close to the face (see Fig. 18). Significantly, on the same shots that produced damage, the beam was nearly diffractionlimited (as indicated by far-field divergence measurements); only a small fraction of the beam energy was involved in the self-focusing.

Removal of the aperture after the spatial filter eliminated the diffraction ring pattern, but the diffraction from the edges of the rods then introduced slight (less than 20\%) fluctuations in the intensity distribution out of the $1 / 2-\mathrm{in}$. rods. After many days of firing at low energy (less than $0.25 \mathrm{~J}$ ), we observed new damage ar about the same place as before, but with a less distinct pattern.

\section{Theoretical}

In our calculation of self-focusing we assumed the input pulse energy to be $2 \mathrm{~mJ}$ and we adjusted the rod gain so that the energy output of the final rod amplifier was $0.25 \mathrm{~J}$. These energy values are representative of values measured for a number of firings of the laser. We used 1.555 for the normal index of refraction of the $\mathrm{Nd}$ :glass and $2 \times 10^{13} \mathrm{esu}$ for $n_{2}$, the power-dependent term of the index of refraction. 28

Figure 19 shows the calculated evolution of the Fresnel diffraction and self-focusing pattern between the aperture and a point $8 \mathrm{~cm}$ before the exit end of the final amplifjer stage, where damage to the glass was first observed. Each of the calculated

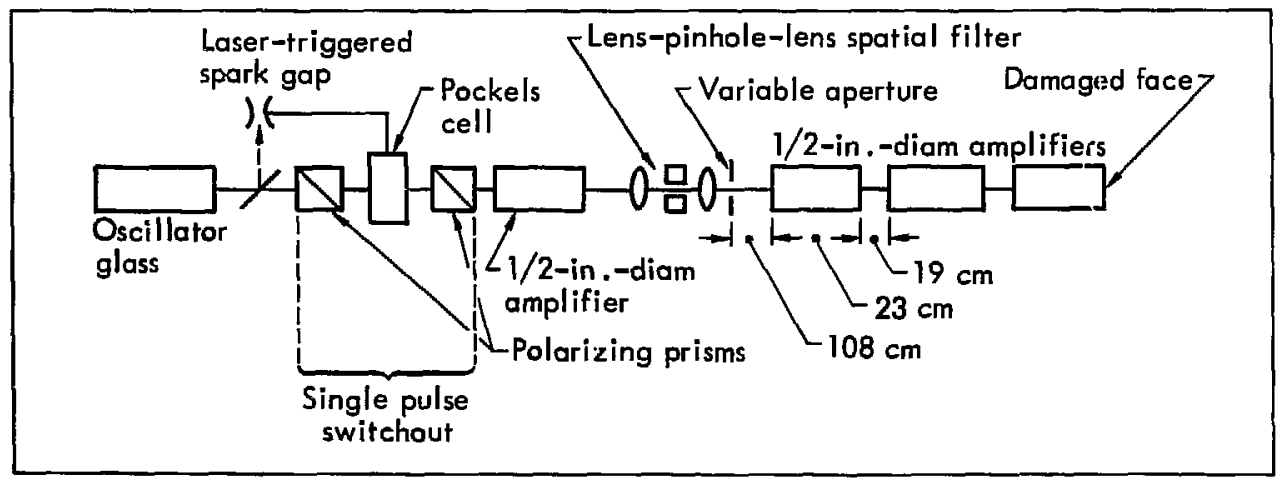

Fig. 17. Portion of the Short Path Laser involved in the self-focusing experiments. 


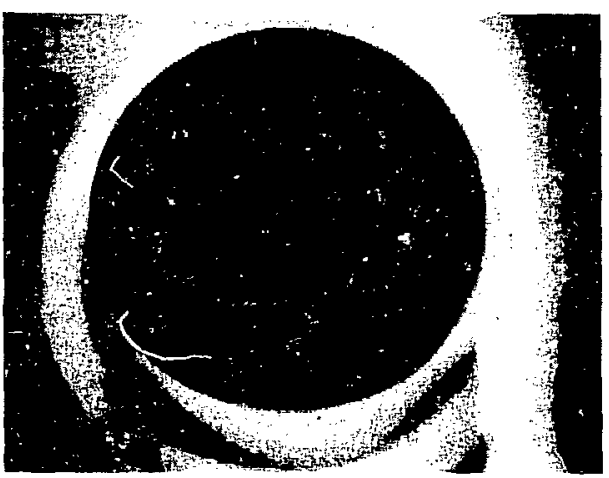

Fig. 18. Damage observed at the end of the 1ast 1/2-ln.-diam Ndiglass emplifier sod.

radial-intensity profiles shown in Fig. 19 corresponds to the time in the pulse when the maximum on-axis intensity occurred.

The positions of the observed fringes (see Fig. 18) are noted at the top of Fig. 19 ty dashed lines. The overall agreement between the observed and the calculated fringe positions is quite good. Only the calculated fringe at a radius of $0.075 \mathrm{~cm}$ is difficult to find in Fig. 18, although there are some spots in the lower half of the rod at the correct radial position for it. The peak intensity occurs at the center of the rod (zero radius). This central maximum, which focuses first, is off-scale in the uppermost profile. The fringes do not change their position between this point and the end of the rod, but they do sharpen considerably.

\section{Conclusions}

Both the experimental and the theoretical results indicate that, in any practisal system, damage levels will be govemed by the quality of the beam. This, in turn, is readily altered (i.e., degraded) by apertures.

Experimental elimination of diffraction effects will require underfilling the rods (i.e., not filling the entire diameter of the rod with the beam), so that the edges aperture the beam at a point of very low intensity. This will be accomplished by reducing the expansion of the spatial filter. However, the most promising solution to self-focusing problems is to use a longer pulse - pehaps 100 psec or more. ${ }^{29}$ By narrowing the bandwidth of an yttrium-aluminum-garnet (YAG) oscillator with intracavity etalons, a longer pulse can be produced. Even if this effort does not give 100-psec pulses, at least we will ebtain a bandwidth-limited pulse from the YAG. We are now susing or preparing to use such oscillators on our other Nd:glass systems. We can then investigate self-focusing further using a well-understood pulse.

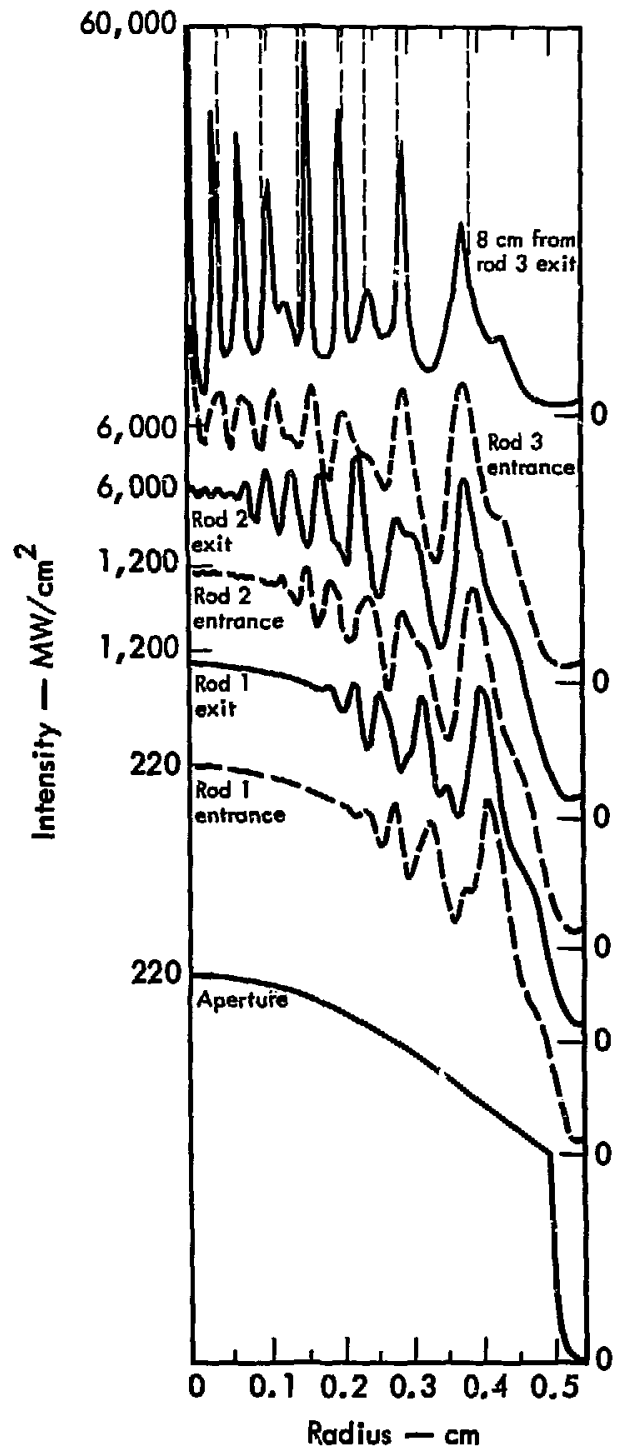

Fig. 18. Relffocusing cocurs in ings detemined by Fresuel difiraction pattems. Shown here is the evalution of the Breanel pattern from the aperture to the point where evidence of dempte is firet observed $(8 \mathrm{~cm}$ in trom the exit end of the lot rod). Intendity values shown at the left are at or near the maximum intengity cilculated at exch pocition. Intenxity at rulius zero (center of the rod) for the top curve is off-esale. Dahed lines at top mirk the podtions of the fringes in the demese pattem hown in Fig. 18. 
Recent Laboratory studies of holography and its applications to nondestructive testing have resulted in a double-exposure holographic method for inspecting the welds of pressure vessels, a holographic technique for plasma diagnostics, and a method of implanting third-dimensional information in two-dimensional $x$-ray shadowgraphs. We have also doveloped a pulsed ruby laser system that operates in a single longitudinal and transverse mode and have studied the "chirping," or frequency shift with time, that occurs in its pulses. We are working on a holographic technique for analyzing picosecond infrared pulses.

A hologram is a record of interference patterns between light waves reflected or diffracted by an object and a suitable reference light wave. If the phase relation between the illuminating and reference waves remains constant in time and space (i.e., if the light is coherent), the hologram then records both the amplitude and the phase of the reflected light, whereas ordinary photographs record only light amplitude.

Since holograms contain this phase information, they can be used to reconstruct a replica of the original light wave that exhibits the parallax, perspective, and depth of field of the original three-dimensional object. This is achieved by illuminating the hologram with a coherent light beam similar to the original reference beam.

\section{Double-Exposure Holography}

One of the properties of holography is that several overiapping holograms can be stored on the same photographic plate. This is the basis of holographic interferometry, in which one makes two exposures, a "before" and an "after," on the same recording emulsion. Upon reconstruction, the two images will interfere, giving a measurable account of what happened during the time between the two exposures. Holographic interferometry is simpler than conventional optical interferometry, and the painstaking alignment of components is not required.

Our first use of double-exposure holography in nondestructive testing was to study the quality of the weld around the equator of metal hemishells welded together to make pressure vessels. By making one exposure of the vessel at amblent pressure and another at high pressure, we can determine the uniformity of the weld (see Fig. 19) and measure quantitatively the distortion of the vessel and the displacement of the seam at a variety of pressures. Promising results in initial tests proved the feasibility of this technique, and we have now adopted it as one of our standard nondestructive-testing methods for a variety of applications.

The double-exposure technique is also useful for observing the electron density in plasmas as a function of time. Its simplicity, lack of critical alignment requirements, and modest optical-quality requirements relative to conventional interferometry tnake it a better choice in plasma diagnostics. This is of particular interest in the laser-fusion program, and we now have a holographic diagnostic effort under way as part of tisat program.

\section{Pulsed Holography and Chirping}

Pulsed holography refers to the technique of making holograms using short pulses of laser light. Among its advantages over continuous-wave holography are that the difficulty of stabilizing holographic equipment is eliminated and its stop-action capability extends the

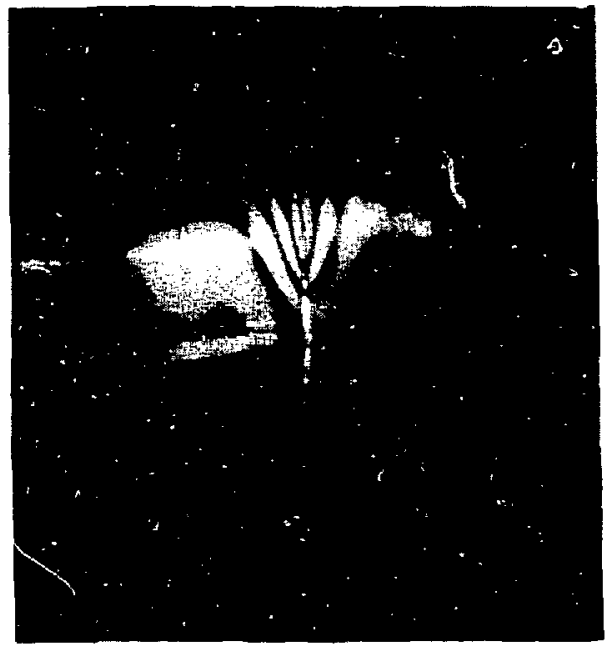

Fig. 19. Image of a double-exposure hologram of the weld in an sluminan presune vesel. The closely speced finges in the upper purt of the picture mark condderable strain in the part of the weld that penetrated coly $25 \%$ of the emminum. The relutively strain-free weld in the lowrer part of the picture had a penetration of 75\%. 


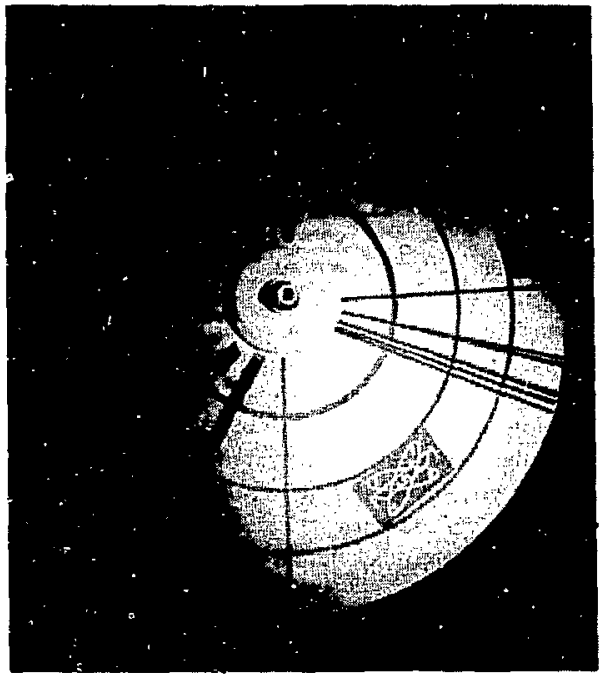

Fig. 20. Photogriph of the holomin-meontructed inate of - 20-anding didk rothting at $9400 \mathrm{mp}$. The im

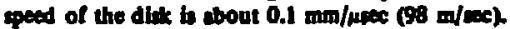
The repolution time of this technique is meh that even at this toxt in aped there is on difterence in the chrity of the boloretiplic mate and that of the ectual object.

use of holographic techniques to many transient phenomena, such as reactions in plasmas.

The chief difficulty in pulsed holography is that the many modes of the output of a normal Q-switched laser limil the coherent length of the light. To overcome this problem we have developed a ruby laser syster that operates in a single longitudinal and transverse mode. ${ }^{19}$ The system uses a saturable dye absorber for Q-switching, an etalon resonant reflector and intracavity pinhole for mode selection, and an amplifier for increasing the output energy to a usable level. The single-mode pulses have an FWHM of 5 to 10 nsec. Figure 20 is an example of a pulsed hologram obtained with this system.

Although our Q-switched laser puts out pulses of a single frequency, the frequency is not stable in time; it shifts during the pulse. This phenomenon is called frequency chirping, a term borrowed from radar technology. The quality of the pulsed holograms depends on the amount of chirp in the laser pulse. We have experimentally studied the correlation between the magnitude of the frequency shift, the relative brightness of holograms made with various path-length differences between the two beams, and the visibility of the interference fringes, which is related to the degree of coherence. ${ }^{20}$ We found that the frequency shift was approximately linear in time; the shift rate was $18 \mathrm{MHz} / \mathrm{nsec}$ for a pulse with a 12-nsec FWHM and $57 \mathrm{MHz} / \mathrm{nsec}$ for a 6-nsec pulse. (We shoriened the pulse length by increasing the concentration of the Q-switching dye.)

We then used the same pulses to generate simpic interference holograms. To do this we split the beam and allowed the two parts to superimpose on a photographic plate after having traversed paths of different lengths. After developing the plates we measured the light diffracted (into the first order) as a function of path-length difference. The amount of light diffracted will decrease as the path-length difference increases because the two pulses do not completely overlap in time and because the chirp causes a phase difference which can wash out the fringe pattern that is the source of the hologram.

By measuring the pulse length and the frequency shift we can predict their effects on the diffrection power and the fringe visibility. The incomplete overiap of the pulses implies a decrease in diffrection power or fringe visibility for a characteristic length difference of many meters (essentially the length of the pulses), whereas the measured chirp value i, assuming that the pulses are Gaussian in shape, lead to characteristic lengths of about $60 \mathrm{~cm}$ for the 6-nsec pulse and about $90 \mathrm{~cm}$ for the 12-nsec pulse. The experimental values were about 45 and $75 \mathrm{~cm}$, respectively. The deviation of the pulse shape from Gaussian and the fact that the chirp is not linear at the beginning and end of the pulse probably account for the difrerence between the predicted and measured values.

\section{Peeudoholographic Reproduction of Three- Dimensional X-Ray Images}

Radiograms are two-dimensional x-ray shadowgrams of an object. Since the advent of holography it has been a hope to apply this technique to the $x$-ray region, but the hope has not yet been realized because the $x$-ray laser has yet to be developed. Nevertheless, we have developed a holographic technique by which phase information is implanted in radiograms, 21 resulting in three-dimensional $x$-ray images.

The method involves two steps. The first is to take a sequence of positive transparency shadowgrams, each having a different perspective, using a set of (incoherent) point $x$-ray sources or using a single source and moving it in steps to different positions. The second step is the introduction of phase information by holography. The shadowgranı transparency is placed in close contact with a high-resolution photographic plate. The incoherent $x$-ray point source is replaced by a coherent laser source, with extreme care being taken that the divergence of the beam corresponds exactly to that 
of the incoherent source when the shadowgram was made. In addition, we inlroduce onlo this recording plate - fixed, collimated, refertence luser beam at an oblique angle $\theta$. Then, by repeatisg the process as in the first step, we synthesize a sequence of holograms by placing the coherent yource at the corresponding positions of the $x$-ray source of the shadowgraph. In this way, the phase information is restored through the correct interference between the coherent point souree and the cohterent reference beam. Consequently, the synthetic hologram possesses the intensity distribution from the contect point of the shadowgram and the phase information through the interference of the coherent light. The composite hologram can then produce a three-dimensional image of the object when the hologram is illuminated at an angle $\theta$ from the oppraite side by a collimated laser beam. Precise measurements can be done on the three-dimensionsl image, making this technique a convenient way of studying the internal structure of a three-dimensional object.

\section{Picosecond Holographic Diagnostics}

We are working on a holographic diagnostic technique for picosecond infrared pulses for the laser-fusion program. We hope to be able to determine holographically such paramelars as the spalial coherence of the pulse and its frequency behavior as a function of time.

Our procedure is to switch out a single pulte from the mode-locked Ndiglas laser using a spark-gap-trigoted Pockels cell. ${ }^{22}$ After amplifying the pulse 10 an energy of about I J, we split out a portion of the pulse and compress it 10 an even shorter duration using a poir of diffraction gratings. The compressed pulse is, ir effecl, "known" pulse that can then be combiried on a hologram with the uncompressed pulse; by choosing the proper timing we can make the compressed pulse interact with any part of the uncomprested pulse and thus gain information on the nature of the uncompressed pulse.

At present, we are developing the haser amplifiers for the mode-locked Nd:glass laser. The nexi step, pulse compression, should be achieved in the near future.

Since high-resolution pholographic film is not available for this region of the spectrum (1.06 $\mu \mathrm{m})$, we have to look for other recording means. Thin films of low themoconductivity and combination photoconductor/thermoplastic film are good candidates for this purpose, and we are now investipating their suitability. 
We have built a large-aperture amplifier for 1-nsec luser pulses that uses a uv-preionized TEA $\mathrm{CO}_{2}-\mathrm{N}_{2}$-He discharge. This amplifier has produced peak gains as high as $0.032 \mathrm{~cm}^{-1}$ (i.e., per cm of amplifier length) and reliable gins as high as $0.028 \mathrm{~cm}^{-1}$. Flat and reproducible gins can be obtained over apertures as large as $10.7 \mathrm{~cm}$ in diameter.

Enlarging the aperture size is the easiest solution to sereral problems that arise in the design of $\mathrm{CO}_{2}$ oscillator-amplifier chains for high-energy pulsed operation. The large beam areas help prevent optical breakdown of the gain medium in the amplifiers for I-nsec pulses of the $10.6-\mu \mathrm{m} \mathrm{CO}_{2}$ light. Also, the saturation energy for nanosecond pulses has recently been found to be low, 17 which is of concem for at least two reasons. First, to reach a given output puise energy, one must either maintain the energy per unit area in the propagating pulse at only a few times the saturation energy and increase the beam cross-sectional area accordingly, or one must cbtain a large small-signal gain in a constant aperture. But to obtain large small-signal gains one needs absorbers saturable at $10.6 \mathrm{~mm}$, and satisfactory performance of such absorbers with nanosecond pulses has not yet been demonstrated. Second, if spatially Gaussian input pulses are assumed and diffraction is ignored, the area of the propagating pulse between its half-naximum points increases linearly with distance once the energy of the propagating pulse is larger than the saturation energy. If such a pulse is to be propagated without having significant portions of the beam become too large in diameter for the amplifiers, large-cross-section amplifiers sre needed. For these reasons, the amplification of I-nsec pulses to energies of hundreds of joules will require the excitation of large volumes of gas mixtures with beam apertures of $100 \mathrm{~cm}^{2}$ or more.

One proved way to achieve large-aperture performance in an amplifier is by electronbeam discharges. However, because electronbeam devices are expensive to build and operate, we looked for an alter native among the several ur-preionized-and-sustained

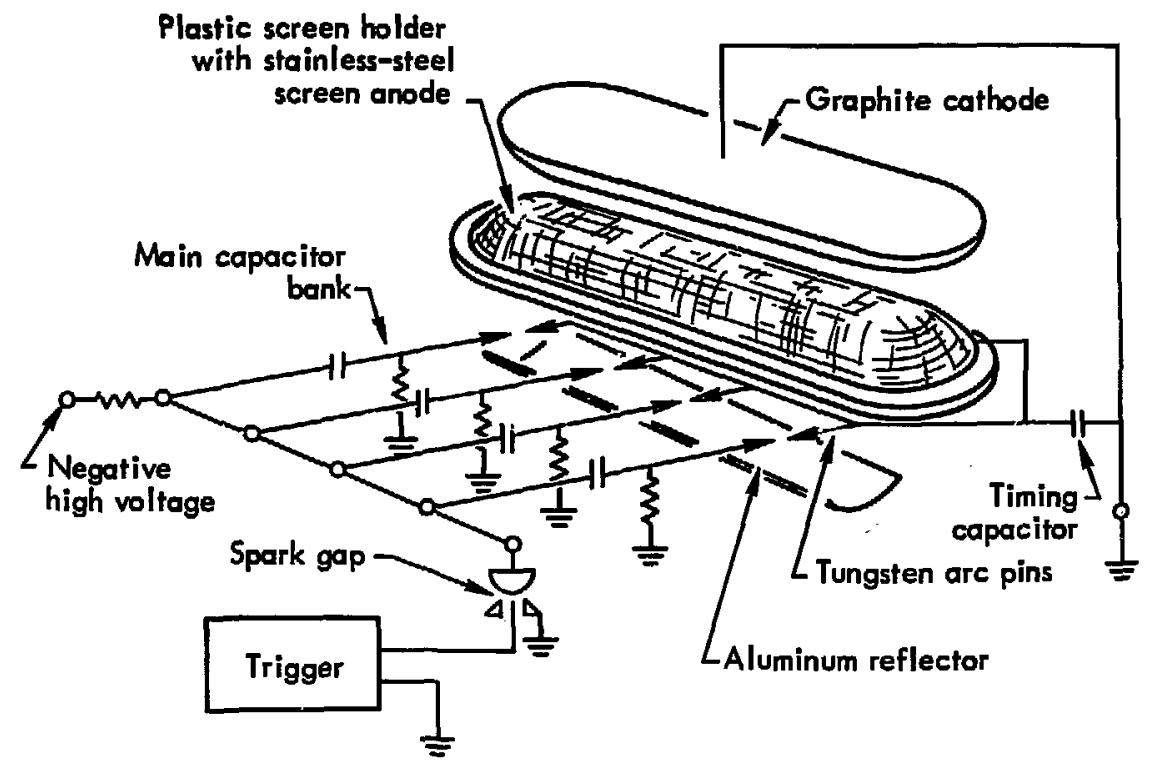

Fig. 11. Schematic drawing of the 50-cm TEA anplifier module. 
devices recently reported. 18,19 In a test chamber similar to that of Seguin and Tulip ${ }^{19}$ we were able to deposit $525 \mathrm{~J} /$ liter at an electrode spacing of $10 \mathrm{~cm}$ into a mixture of $\mathrm{CO}_{2}$, nitrogen, and helium. Lessuniform but still arc-free glow discharges could be produced even when the electrodes were separated by $22.5 \mathrm{~cm}$ (the limit of our apparatus).

Thus encouraged, we fabncaind the 50-cm-long amplifier module shown schematically in Fig. 11. Both the anode and the cathode were cut accurately to a Rogowski equipotential profile calculated for an $8-\mathrm{cm}$ electrode spacing. A uv-preionization pulse was obtained by discharging the main capacitor bank through $301-\mathrm{cm}$ arcs between tungsten pins. The discharge between the main electrodes is adequately delayed to allow uv preionization by choosing a timing capacitor with a value 10 to $20 \%$ of that of the main bank.

This structure has provided extremely uniform and reproducible plasmas in a variety of $\mathrm{CO}_{2}-\mathrm{N}_{2}-\mathrm{He}$

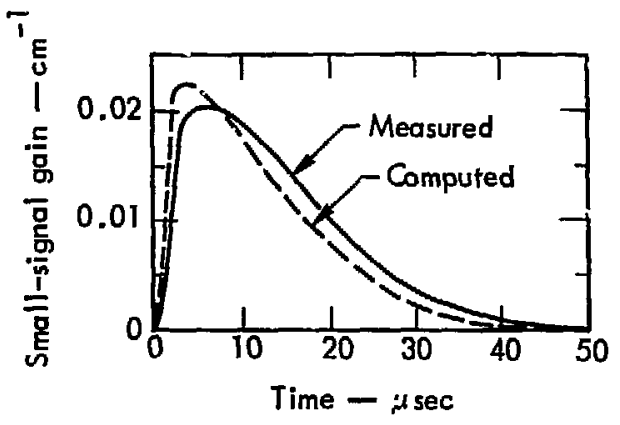

Fig. 12. Typical gain-vatime trace for the $50 \mathrm{~cm}$ anplifier modute.

mixtures. We measured the gain on the P18 transition with a 3-W cW probe laser having an internal grating and operating in the $\mathrm{TEM}_{00}$ mode. Figure 12 compares a typical gain-vs-time trace with the

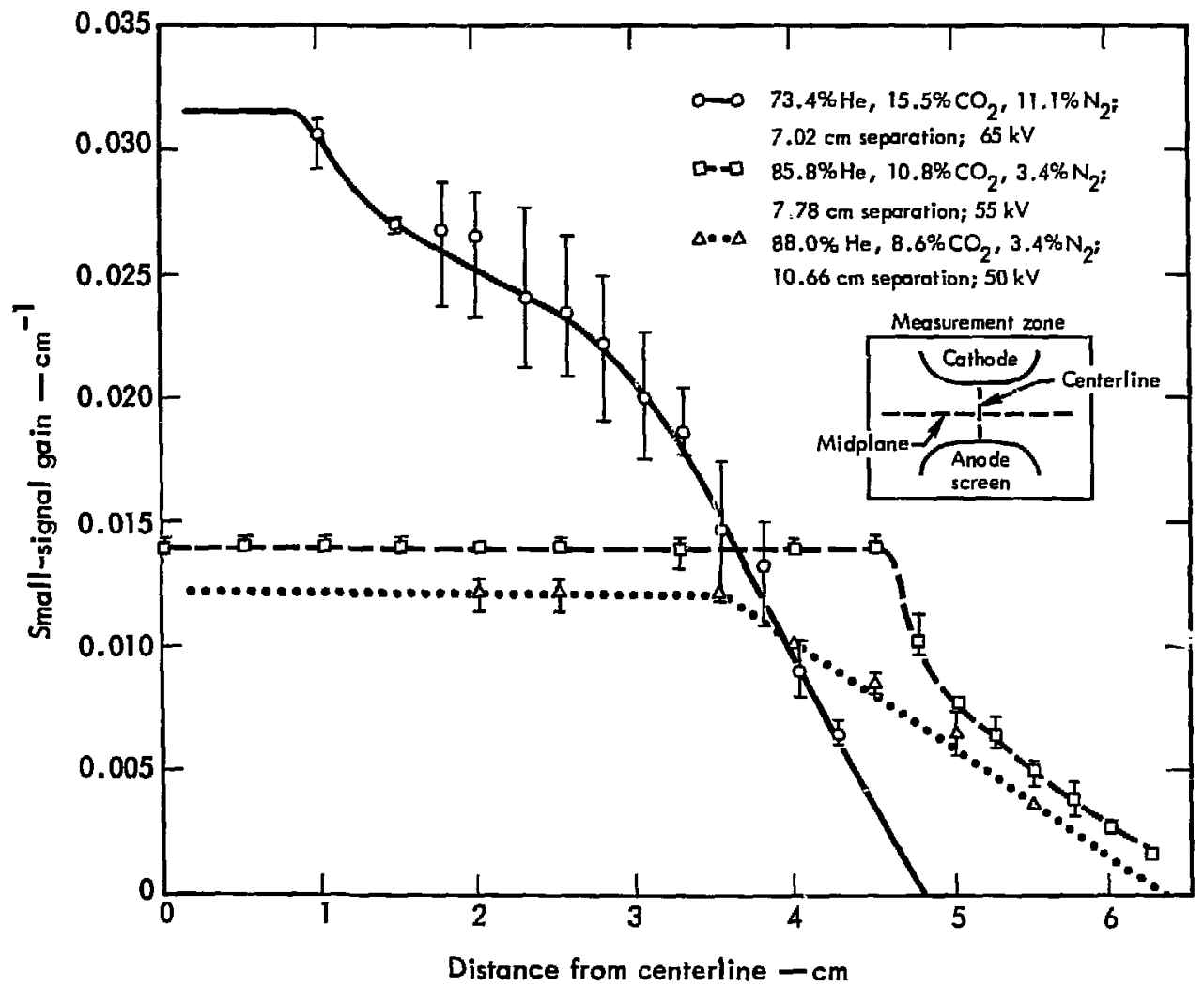

Fig. 13. Gain of the 50-cm amplifier module measured along the midplane between the two electrodes, 
prediction of a five-temperature model of $\mathrm{CO}_{2}$ molecular dynamics. 20

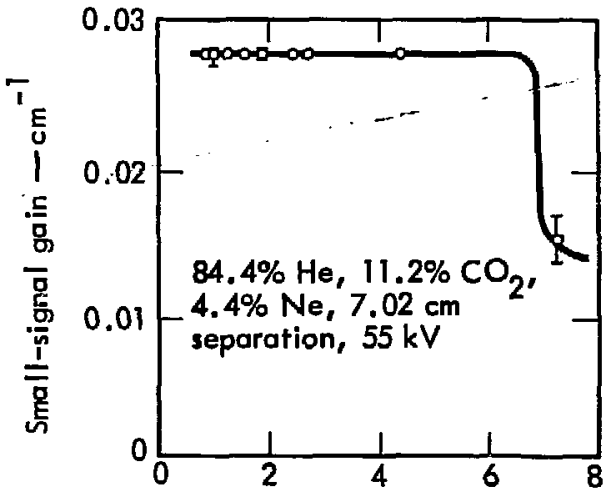

Distance from unode screen $-\mathrm{cm}$

Fig. 14. Gain of the 50-am amplifier module measured along the centerline (nomal to the electrodes). See messurement zone sketch in previous figure.
Figures 13 and 14 show the remarkable uniformity of the gain provided by this amplifier structure. Within the accuracy of the measurement technique, flat and reproducible gain can be obtained over a usable aperture $10.7 \mathrm{~cm}$ in diameter. Uniform discharges have been obtained for electrode separations as large as $12.5 \mathrm{~cm}$; however, the reliable performance ringe corresponded to separations of $10 \mathrm{~cm}$ or less. Still, this is one of the largest-aperture laser amplifiers ever successfully operated.

We have obtained peak gains of $0.032 \mathrm{~cm}^{-1}$, but at the expense of intermittent arcing. The reliable performance range corresponded to gas mixtures and energy depositions yielding gains of $0.028 \mathrm{~cm}^{-1}$ or less. Table 1 gives the electrode separation (beam aperture), gas composition, and applied valtage for several reliable operating points.

When operated as an oscillator with a $9.0-\mathrm{cm}$ aperture and an uncoated germanium output mirror, this device yielded $55 \mathrm{~J}$ per pulse. We measured this energy with a 20 -cm-diam bulk-absorbing thermopile consisting of Teflon sheets on copper. Energy measurements using cone-shaped ballistic thermopiles gave erratic but substantially higher estimates.

Table 1. Parameters of several reliable operating points of the $50-\mathrm{cm}$ module

\begin{tabular}{|c|c|c|c|c|c|c|c|c|}
\hline \multirow{2}{*}{$\begin{array}{l}\text { Ayplied } \\
\text { voltage } \\
\text { (kV) }\end{array}$} & \multirow{2}{*}{$\begin{array}{l}\text { Electrode } \\
\text { Eepantion } \\
\text { (cm) }\end{array}$} & \multirow{2}{*}{$\begin{array}{c}E / P^{2} \\
\text { (V/cm-Totr) }\end{array}$} & \multirow{2}{*}{$\begin{array}{c}\text { Input } \\
\text { energy } \\
\text { (J) }\end{array}$} & \multirow{2}{*}{$\begin{array}{l}\text { Input } \\
\text { energy } \\
\text { density } \\
\text { (o/liter) }\end{array}$} & \multicolumn{3}{|c|}{$\begin{array}{c}\text { Gas composition } \\
(\%)\end{array}$} & \multirow{2}{*}{$\begin{array}{c}\text { Relinble } \\
\text { gmin } \\
\left(\mathrm{cm}^{-1}\right)\end{array}$} \\
\hline & & & & & He & $\mathrm{CO}_{2}$ & $N_{2}$ & \\
\hline so & 7.02 & 9.33 & 280.0 & 111.7 & 84.4 & 11.2 & 4.4 & 0.0280 \\
\hline 50 & 7.02 & 9.33 & 280.0 & 111.7 & 88.0 & 8.6 & 3.4 & 0.0130 \\
\hline S5 & 7.78 & 9.31 & 338.8 & 85.8 & 85.8 & 10.8 & 3.4 & 0.0140 \\
\hline 70 & 7.78 & 11.91 & 548.8 & 138.9 & 85.8 & 10.8 & 3.4 & 0.0131 \\
\hline s5 & 7.78 & 9.31 & 338.8 & 85.8 & 82.0 & 11.2 & 6.8 & 0.0195 \\
\hline 55 & 7.78 & 9.31 & 453.5 & 115.0 & 86.4 & 8.7 & 4.9 & 0.0191 \\
\hline 55 & 10.66 & 6.79 & 338.8 & 66,2 & 88.0 & 8.6 & 3.4 & 0.0121 \\
\hline
\end{tabular}

${ }^{\mathrm{a}} \mathrm{E} / \mathrm{P}$ is a measure of the electron mobility:

$E / P=\frac{\text { (voltage) }}{\text { (electiode separation) } \times \text { (gas pressure) }}$.

\section{SHORT-PULSE GENERATION AND AMPLIFICATION IN A $\mathrm{CO}_{2}$ TEA LASER OSCILLATOR-AMPLIFIER}

We have amplified a single 1-nsec $\mathrm{CO}_{2}$ laser pulse to an energy of $2 \mathrm{~J}$ in a simple system consisting of an LLLbuilt mode-locked extemally switched TEA oscillator and two commercially built TEA amplifiers, with an effective aperture of $25 \mathrm{~mm}^{21}$ This energy represents a flux of about $400 \mathrm{~mJ} / \mathrm{cm}^{2}$ in the output beam, which is about 10 times the available stored energy in a single $\mathrm{CO}_{2}$ rotational transition in the 


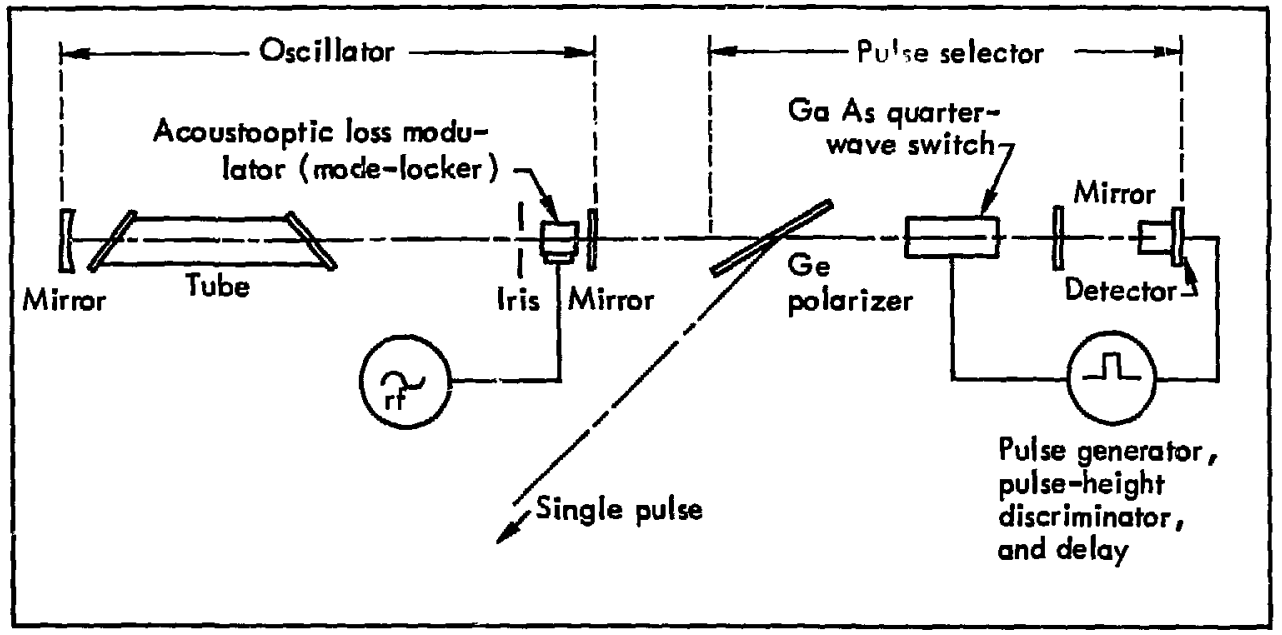

Fig. 16. The LLLbuilt TEA oscilntor, actively modelocked and externsty witched.

amplifier chain. This high flux can be explained in terms of conventional single-line output theory if the rotational cross-relaxation times between the various transitions available in the $10.6-\mu \mathrm{m} P$-branch of $\mathrm{CO}_{2}$ are much less than 1 nsec, as the data of Cheo and Abroms suggest. 22 However, spectral measurements show that our system is not lasing on a single line but rather on a number of lines simultaneously; as many as 12 have been observed. Thus we do not have single-line output but rather multiline output. Some cross-relaxation must also be occurring, for the $\boldsymbol{P 2 0}$ line contains about half the total intensity of all the lines, a disproportionately large share according to our theoretical studies. Hence the explanation for the high flux level appears to be a combination of multiline output and some cross-relaxation of the rotational transitions. We have a theoretical model under development.

Figure 15 shows the LLL TEA oscillator. ${ }^{23}$ The principal difference between this and other oscillators is the use of a three-section Lamberton-Pearson gain medium $^{24}$ whose active length is $150 \mathrm{~cm}$. The single-pass small-signal gain of this device is of the order of 50 .

A typical mode-locked train of light pulses sampled before switchout contains $70 \mathrm{~mJ}$ in a train of about 15 1-nsec pulses. After switchout, aperturing and attenuation reduce the energy of the switched-out peak pulse to $1: 0 \mathrm{~mJ}$ in a $5-\mathrm{mm}$-diam beam. The magnitudes of pre- and post-pulses are reduced by a factor of at least 200 relative to that of the switched-out pulse. In the far field ( $5 \mathrm{~m}$ or more beyond the oscillator) the output is nearly diffraction limited. To measure the far-field pattern we used a 128-element linear array of pyroelectric detectors. Figure 16 shows a typical trace of such a measurement. Inside the gain medium the circulating pulse has a peak energy of about $30 \mathrm{~mJ}$, corresponding to a flux of about $60 \mathrm{~mJ} / \mathrm{cm}^{2}$ in the lasing volume.

The amplifiers used in this study were manufactured by Lumonics Research Ltd., Ottawa, Ont. Each amplifier has an effective aperture of $25 \mathrm{~mm}$ and a gain length of $1.35 \mathrm{~m}$. The gas mixture was $86 \%$ helium, $7 \%$ nitrogen, and $7 \% \mathrm{CO}_{2}$. From the oscillator exit it is $3 \mathrm{~m}$ to the entrance of the first amplifier and $8 \mathrm{~m}$ to the exit of the second amplifier.

We measured the small-signal gain of each amplifier to be $0.025 \mathrm{~cm}^{-1}$ on the device centerline, or 50 per

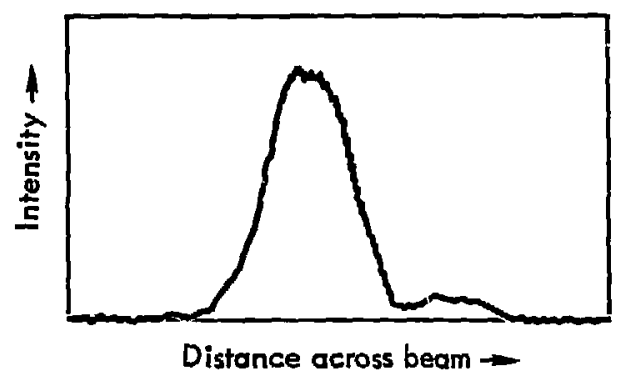

Fig. 16. Far-field intensity profile of the output of the LLL oscillator. 


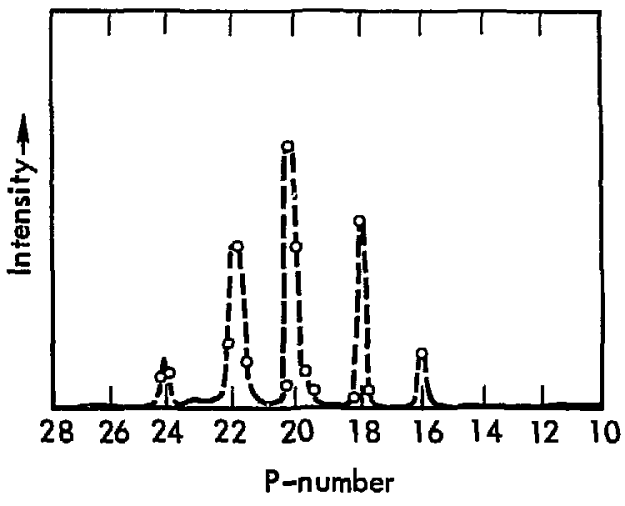

Fig. 17. Output spectrum of the LLL oscillator obteined with a pyroelectric array detector.

pass. Within the effective aperture the small-signal gain drops off as much as $20 \%$ on a vertical scan away from the centerline, but no more than $10 \%$ in a horizontal scan. From this small-signal gain and the saturation energy flux $\left(9.8 \mathrm{~mJ} / \mathrm{cm}^{2}\right)$, we calculate that the maximum extractable energy flux of each amplifier is $33 \mathrm{~mJ} / \mathrm{cm}^{2}$ per pass when it is operating on a single transition, neglecting cross-relaxation effects. If, on the other hand, cross-relaxation is effective or if the amplifier input spectrum contains an equal amount of energy in all rotational lines, the saturation flux is about $160 \mathrm{~mJ} / \mathrm{cm}^{2}$, and a considerably larger amount of extractable energy is available.

In fact, we have repeatedly propagated a $1-\mathrm{mJ}$, 1-nsec pulse through our amplifier chain at peak gain and obtained an energy output of $2.0 \pm 0.5 \mathrm{~J}$. This corresponds to an energy density of about $400 \mathrm{~mJ} / \mathrm{cm}^{2}$, extracted mainly from the second amplifier. We believe there is little possibility that any significant part of this amplified output arises from amplification of a long, low-level signal, since we have removed the nitrogen-caused tail from our oscillator output pulses by judicious selection of the gas mixture, and since the switchout device attenuates the oscillator output by a factor of 200 or more except during a single 5-nsec window. Also, we have directly observed that the amplified signal has no perceptible amplitude after the single pulse.

In an attempt to resolve this disparity between the measured extracted energy flux and that projected (neglecting cross-relaxation effects), we scanned the spectrum of the oscillator using a small spectrograph with liquid-crystal and graphite tagets at the exit focal plane of the oscillator. We routinely saw as least four lines, occasionally six.
We then set up a 5-m spectrometer designed for an f-number of 50, which gives an expected diffraction-limited spot size at the exit plane of $0.6 \mathrm{~mm}$. With the focal lengths and diffraction grating we used, the dispersion is about $0.6 \mathrm{~mm} / \mathrm{nm}$, piving a spread of about $12 \mathrm{~mm}$ between adjacent rotational transitions of $\mathrm{CO}_{2}$ (the line spacing is $20 \mathrm{~nm}$ at the wavelength of the $P 20$ transition). This dispersion spreads the linewidth of each transition over about $0.55 \mathrm{~mm}$ at the exit plane, which is necessary to ensure that no line falls between the elements of our pyroelectric linear-array detector, which has a dead space of $0.1 \mathrm{~mm}$ between elements.

With the detector array at the spectrometer exit plane we obtained results such as those in Fig. 17 for the oscillator output. Unfortunately, for quantitative work this approach was not accurate enough. The peak intensities include a possible error of $\pm 50 \%$ due to the chance that one line illuminated two detector elements rather than one. However, the array measurements established beyond a doubt that the oscillator lases on several rotational lines simultaneously.

To quantitatively measure the spectral content on each transition, we substituted for the pyroelectric array a $\mathrm{Ge}: \mathrm{Cu}$ liquid-helium-cooled detector. To correct for the nonlinearity of this detector, we maintained the measured signal between 0.5 and $5 \mathrm{~V}$ by inserting calibrated attenuators in the measured beam. In this way the actual measurentent was kept accurate to within $10 \%$. Figure 18 gives the results of these measurements, which show that at least $50 \%$ of the oscillator output is on the $P 20$ line.

We then measured the output spectrum of the entire oscillator-amplifier chain (actively mode-locked) by attenuating the amplified oscillator output and sending it to the spectrometer. We deliberately tried to saturate both amplifiers by placing a slightly focused 2-power beam-expanding telescope between the oscillator and the amplifiers; this expanded the beam diameter to $11 \pm 1 \mathrm{~mm}$ in both amplifiers in the absence of pumping. With the amplifiers pumped, the exit spot size is difficult to restrict, due to saturation effects. The apparent core of the amplified beam (the bum spot on Polaroid film) was about $20 \mathrm{~mm}$ in diameter.

Figure 18 shows the spectrum resulting from saturated amplification of the oscillator output. In this spectrum the intensity of the $P 20$ line is still about half the total intensity of all the lines. In fact, the spectrum is somewhat narrower after amplification than before. In all the spectra we obtained, the intensity decreases exponentially as the $\boldsymbol{P}$-number increases or decreases from 20 , and each spectrum is skewed toward the lower $P$-numbers. Since we made spectral measurements over a period of several weeks, the agreement between spectra measured under similar 
conditions is impressive evidence that the observed behavior is repeatable.

In a classical laser oscillator, single-line operation is achieved by cross-relaxation of the rotational levels into the transition having the highest gain. Measurement of the spectrum of the spiked output of a mode-locked oscillator with variable spike duration is one way of estimating the effective cross-relaxation time independent of theoretical prediction. If the spike is much shorter than the cross-relaxation time between rotational levels, then cross-relaxation will not be able to effect single-line output.

Let us assume that the duration of the spike is shorter than the cross-relaxation time and shorter than the time it takes the light to make a round trip through the cavity. Under these conditions relaxation effects will not have time to prevent multiline lasing during a spike, but there will still be enough time to equilibrate between rotational levels during a cavity round trip. Then, using the simple theory of a sarurating amplifier and making a number of simplifying assumptions, we can derive what the oscillator output spectrum should be, based on the Boltzmann population of the rotational states of $\mathrm{CO}_{2}$. Figure 18 shows the calculated result.

Quantitatively, this calculated curve is a very poor predictor of the observed spectra except that it does predict vanishing intensity at the correct pair of $P$-values and it gives the correct peak $P$-value. However, it should be recalled that, if the rotational lines equilibrated in a time very short compared with the mode-locked pulse width, the output spectrum of our oscillator would have consisted of a single line at $P 20$. The calculated curve in Fig. 18 represents the opposite extreme - the rotational lines do not equilibrate at all during a mode-locked pulse. Our experimental data suggest that the truth lies between these extremes - namely, that the spike duration is only somewhat longer than the cross-relaxation time. We are now doing a computer analysis that retains both rotational and vibrational equilibration during the mode-lockeả pulse.

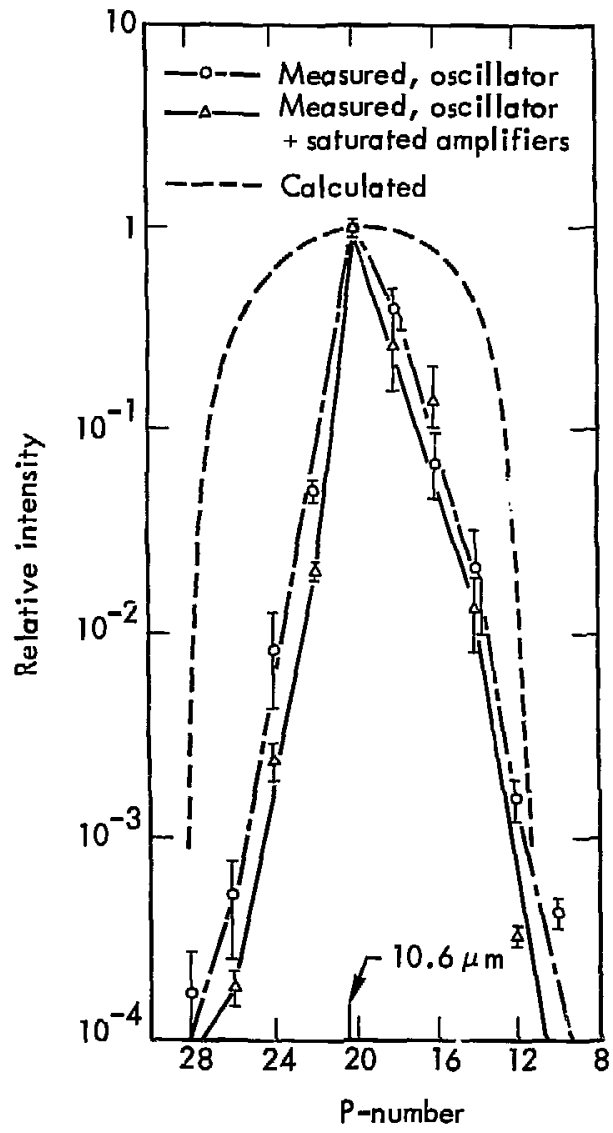

Fig. 18. Quantitative output spectra of the LLL oscillator and oseillator-amplifier chain. The observed spectra were obtained using a $\mathrm{GetCu}$ detector. The calculated epectrum is brsed on the Boltrmann population of the rotational states of $\mathrm{CO}_{2}$, assuming that the spike duration is shorter than the rotational cross-reloxation time. 


\section{Notes and References}

pp. $1-7$

14. For a description of our recent work on the vacuum-ultraviolet emissions of rare gases at low pressures, see LLL Laser Projects Report No. 3, G. I. Kachen and G. Shaw, Eds., Lawrence Livermore Laboratory Rept. UCRL-50022-3 (1972), pp. 10-15. Also described there is much of the basic theory underlying the experiments reported here.

15. N. G. Basov, V. A. Danilychev, Yu. M. Popov, and D. D. Khodkevich, Sov. Phys. - JETP Letters 9, 329 (1970).

16. A. G. Molchanov, I. A. Polnektov, and Yu. M. Popov, Sov. Phys. - Solid State 9, 2655 (1968).

17. The calibration was done by V. Pereskokov at Stanford University, Yalo Alto, Calif.

18. G. S. Hurst, T. E. Stewart, and J. E. Parks, Phys. Rev. A 2, 1717 (1970).

19. M. G. Vitkov, Opt. Spectrosc. 34, 420 (1968).

20. The plasma X laser is described in $L L L$ Laser Projects Report No. I, G. I. Kachen and G. Shaw, Eds., Lawrence Livermore Laboratory Rept. UCRL-50022-1 (1972), p. 1.

pp. 8-10

13. It should be noted that, because a saturable isolator bleaches at high intensities, it can only prevent problems due to prelasing; high-intensity reflections will still be able to retum through the system.

14. Heated $\mathrm{CO}_{2}$ may not absorb strongly enough to act as a good attenuator and be efficiently bleached. It has Esen demonstrated that heated $\mathrm{CO}_{2}$ does saturate and bleach.

15. The TEA laser is described in $L L L$ Laser Projects Report No. I, G. I. Kachen and G. Shaw, Eds., Lawrence Livermore Laboratory Rept. UCRL-50022-1 (1972), p. 14.

pp. 11-17

27. J. A. Stamper, K. Popadopoulos, R. N. Suđan, S. O. Dean, E. A. McLean, and J. M. Dawson, Phys. Rev. Lett. 26, 1012 (1971):

28. The MOKU code is described in Military Application Programs Monthly Report - April 1968, Lawrence Livermore Laboratory Rept. UCRL-50000-68-4 (title U, report SRD).

29. This work is described in detail in J. B. Chase, J. L. LeBlanc, and J. K. Wilson, The Role of Spontaneous Magnetic Fields in a Laser Created Deuterium Plesma, Lawrence Livermore Laboratory Rept. UCRL-73914 (1972); submitted to Phys. Fluids.

30. Anomalous absorption mechanisms are discussed in the article on laser-plasma coupling in the May 1972 monthly report (UCRL-50000-72-5).

31. The experimental results are those of F. Floux, J. F. Benard, D. Cognard, and A. Saleres, reported at the August 1971 Gordon Conference under the title "Nuclear D-D Reactions in Solid Deuterium Laser-Created Plasma."

32. See, for example: N. G. Basov, V. I. Igoshin, E. P. Markin, and A. N. Graevskii, Sov. J. Quant. Electron. I, 119 (1971); A. N. Oraevskii, Sov. Phys. - JETP 28, 744 (1969); V. L. Tal'rose, G. K. Vasil'ev, and O. M. Batovskii, Kinet. Catal. 11, 233 (1970); and M. S. Dzhidzhoev, V. T. Platonenko, and R. V. Khokhlov, Sov. Phys. - Usp. 13, 247 (1970).

33. Y. -L. Pan, C. E. Turner, Jr., and K. J. Pettipiece, Chem. Phys. Lett. 20, 577 (1971).

34. R. K. Pearson, J. O. Cowles, G. L. Hermann, D. W. Gregg, and J. R. Creighton, Relative Performance of a Variety of $\mathrm{NF}_{3}+$ Hydrogen-Donor Transverse Discharge HF Chemical Luser Systems, Lawrence Livermore Laboratory Rept. UCRL-73663 Preprint (1972); submitted to IEEE J. Quant. Electron.

35. The double-discharge $\mathrm{CO}_{2}$ laser is described in the November 1971 monthly report (UCRL-50000-71-11).

36. This claim was attributed to A. N. Oraevskii by A. N. Chester in his review of chemical laser work (Paper N.1) at the 7th International Quantum Electronics Conference, Montreal, May 8-11, 1972.

37. N. G. Basov, private communication to C. E. Turner, Jr. (LLL), 1972. 
28. This value of $n_{2}$ is that of M. A. Duguay, J. W. Hansen, and S. Shapiro, IEEE J. Quant. Electron. QE-6, 725 (1970).

29. Self-focusing depends on the instantaneous power. A longer pulse will reduce the peak power attained, thus raising the threshold energy for self-focusing.

pp. 20-25

17. F. Rheault, J. L. Lachambre, J. Gilbert, R. Fortin, and M. Blanchard, "2 GW Peak Power Generation from a TEA CO${ }_{2}$ Oscillator-Amplifier Laser," 7th International Quantum Electronics Conference, Montreal, Que., May 8, 1972; J. F. Figueira, W. H. Reichelt, G. T. Schappert, T. F. Stratton, and C. A. Fenstermacher, "Nanosecond Pulse Amplification in Electron Beam Pumped $\mathrm{CO}_{2}$ Amplifiers," 1972 Conference of the American Physical Society Division of Plasma Physics, Monterey, Calif., Nov. 16, 1972.

18. O. P. Judd, "An Efficient Electrical $\mathrm{CO}_{2}$ Laser Using Preionization by Ultraviolet Radiation," 1972 Coríerence of the American Physical Society Division of Plasma Physics, Monterey, Calif., Nov. 16, 1972.

19. H. Seguin and J. Tulip, Appl. Phys. Lett. 21, 414 (1972).

20. K. R. Manes and H. J. Seguin, J. Appl. Phys. (in press).

21. TEA lasers are described in detail in the December 1971 monthly report (UCRL-50000-71-12).

22. P. K. Cheo and R. L. Abrams, Appl. Phys. Lett. 14, 47 (1969).

23. The LLL oscillator is described in detail in the Laser-Fusion Program Semiannual Repart - January-June 1972, Lawrence Livermore Laboratory Rept. UCRL-50021-72-1 (1972), pp. 36-38.

24. P. H. Pearson and H. M. Lamberton, IEEE J. Quant. Electron. QE-8, 145 (1972).

Pp. 26-28

19. The single-mode ruby laser system is described in detail in $\mathbf{H}$. H. Chau and $\mathbf{G}$. W. Leppelmeier, Nanosecond-Pulse Holography, Lawrence Livermore Laboratory Rept. UCID-15677 (1970).

20. The results of the chirping study are given in detail in H. H. Chau and G. W. Leppelmeier, J. Opt. Soc. Amer. 61, 998 (1971).

21. The three-dimensional reproduction of shadowgrams is described in detail in H. H. Chau, Opt. Commun. 4, 1 (1971).

22. The spark-gap-triggered Pockels cell is described in the July 1972 monthly report (UCRL-50000-72-7). 